\title{
biomolecules
}

ISSN 2218-273X

www.mdpi.com/journal/biomolecules/

Review

\section{The Role of the COP9 Signalosome and Neddylation in DNA Damage Signaling and Repair}

\section{Dudley Chung ${ }^{1, \dagger}$ and Graham Dellaire ${ }^{1,2, \dagger, *}$}

1 Department of Pathology, Dalhousie University, Halifax, NS B3H 4R2, Canada;

E-Mail: dudleyc@dal.ca

2 Department of Biochemistry and Molecular Biology, Dalhousie University, Halifax, NS B3H 4R2, Canada

$\dagger$ These authors contributed equally to this work.

* Author to whom correspondence should be addressed; E-Mail: dellaire@dal.ca; Tel.: +1-902-494-4730.

Academic Editors: Wolf-Dietrich Heyer, Thomas Helleday and Fumio Hanaoka

Received: 30 June 2015 / Accepted: 21 September 2015 / Published: 30 September 2015

\begin{abstract}
The maintenance of genomic integrity is an important process in organisms as failure to sense and repair damaged DNA can result in a variety of diseases. Eukaryotic cells have developed complex DNA repair response (DDR) mechanisms to accurately sense and repair damaged DNA. Post-translational modifications by ubiquitin and ubiquitin-like proteins, such as SUMO and NEDD8, have roles in coordinating the progression of DDR. Proteins in the neddylation pathway have also been linked to regulating DDR. Of interest is the COP9 signalosome (CSN), a multi-subunit metalloprotease present in eukaryotes that removes NEDD8 from cullins and regulates the activity of cullin-RING ubiquitin ligases (CRLs). This in turn regulates the stability and turnover of a host of CRL-targeted proteins, some of which have established roles in DDR. This review will summarize the current knowledge on the role of the CSN and neddylation in DNA repair.
\end{abstract}

Keywords: COP9 Signalosome; DNA repair; NEDD8 


\section{Introduction}

\subsection{The COP9 Signalosome}

The COP9 Signalosome (CSN) is a multi-subunit protein complex that was identified in the 1990s in Arabidopsis as a repressor of photomorphogenesis [1], and was later found conserved in other unicellular and multicellular eukaryotes [2-7]. In eukaryotes that have simpler CSN complexes, such as yeast, several subunit deletions are viable [8-10]. However, null deletions in other organisms are lethal early in development [11-13], and conditional knockouts result in developmental phenotypes and impaired cellular functional [14], suggesting an increase in functional complexity as the CSN evolved. The role of the CSN is to deneddylate substrates, particularly cullin-RING E3 ubiquitin ligases (CRLs) in the ubiquitin proteasome pathway [15,16]. In addition, early attempts to biochemically isolate and characterize the CSN protein complex found it to be associated with kinase activity [2], which the molecule curcumin was able to inhibit [17]. Later studies identified the kinases that interact with the CSN to impart the complex with associated kinase activity. Examples include protein kinase CK2 (CK2) [18,19], protein kinase D (PKD) ([18], protein kinase B-Akt (Akt) [19], ataxia telangiectasia mutated (ATM)[20], and inositol 1,3,4-triphosphate 5/6 kinase [21]. These kinases modify the stability of ubiquitin-mediated proteasomal substrates. Since its discovery, researchers have begun to uncover roles for the CSN and the neddylation pathway in the DNA damage response (DDR). This review will explore the molecular mechanism of the CSN and current knowledge of its role in DNA damage signaling and repair.

\subsection{CSN Architecture and Expression}

The mammalian CSN holoenzyme consists of eight subunits (CSN1 to CSN8) [2,4]. Six of the eight subunits (CSN1-4, and CSN7-8) contain a PCI (proteasome, COP9, initiation factor) domain, a feature shared with subunits of both the 19S proteasome regulatory complex and eiF3 complex, suggesting a common evolutionary origin [17,22]. Furthermore, studies suggest these complexes can interact with one another [4,22-24]. CSN5, which is also called Jun activation domain-binding protein-1 (Jab1) [25], and CSN6 both contain an MPN (MPR1-PAD1-amino terminal) domain [26]. Unlike CSN6, the MPN domain in CSN5 contains a $\mathrm{Zn}^{2+}$ binding JAMM (JAB1/MPN/Mov34) motif, thus making it the sole catalytically active subunit in the CSN [10]. The metalloprotease JAMM/MPN motif possesses the His-X-His-X10-Asp consensus sequence (where $\mathrm{X}$ indicates any amino acid residue) accompanied by a conserved glutamic acid upstream [26]. In addition, mammals express two forms of CSN7 (CSN7a and CSN7b) and CSN complexes likely contain either one or the other of these two isoforms [27].

Recent investigation of the individual subunits and of the CSN holoenzyme provided new details to its organization [28-34] (Figure 1). Current understanding is that the winged-helix domains of the PCI domains (PCI ring) of CSN1-4 and CSN7-8 are arranged as an open ring such that the N-terminal helical repeat domains of these subunits radiate out from it while the carboxy terminal helical tails form a bundle that anchor the complex [31,33-35]. The MPN domains of the CSN5-CSN6 heterodimer rest on the helical bundle while their carboxy terminal helical tails are inserted into the helical bundle. Integration of CSN5 into the complex is abrogated by the absence of CSN6, but deleting CSN1, 2, 4, or 7 can also disfavor CSN5 integration [34]. CSN4 and CSN6 appear to be the most important for stabilizing 
and converting CSN5 into its active state, which was recently found to involve rearrangement within CSN5 to open the NEDD8 binding pocket $[11,34,36]$ but full enzymatic activity in vitro requires the complete set of subunits [29]. The peripheral association of CSN5 with the complex is dynamic since free/monomeric CSN5 is a feature found in different organisms. However, evidence suggests that free CSN5 is essentially catalytically inactive [11,26,29,36-39]. Nonetheless, one cannot rule out an as yet to be identified non-catalytic role for free CSN5 in the cell.

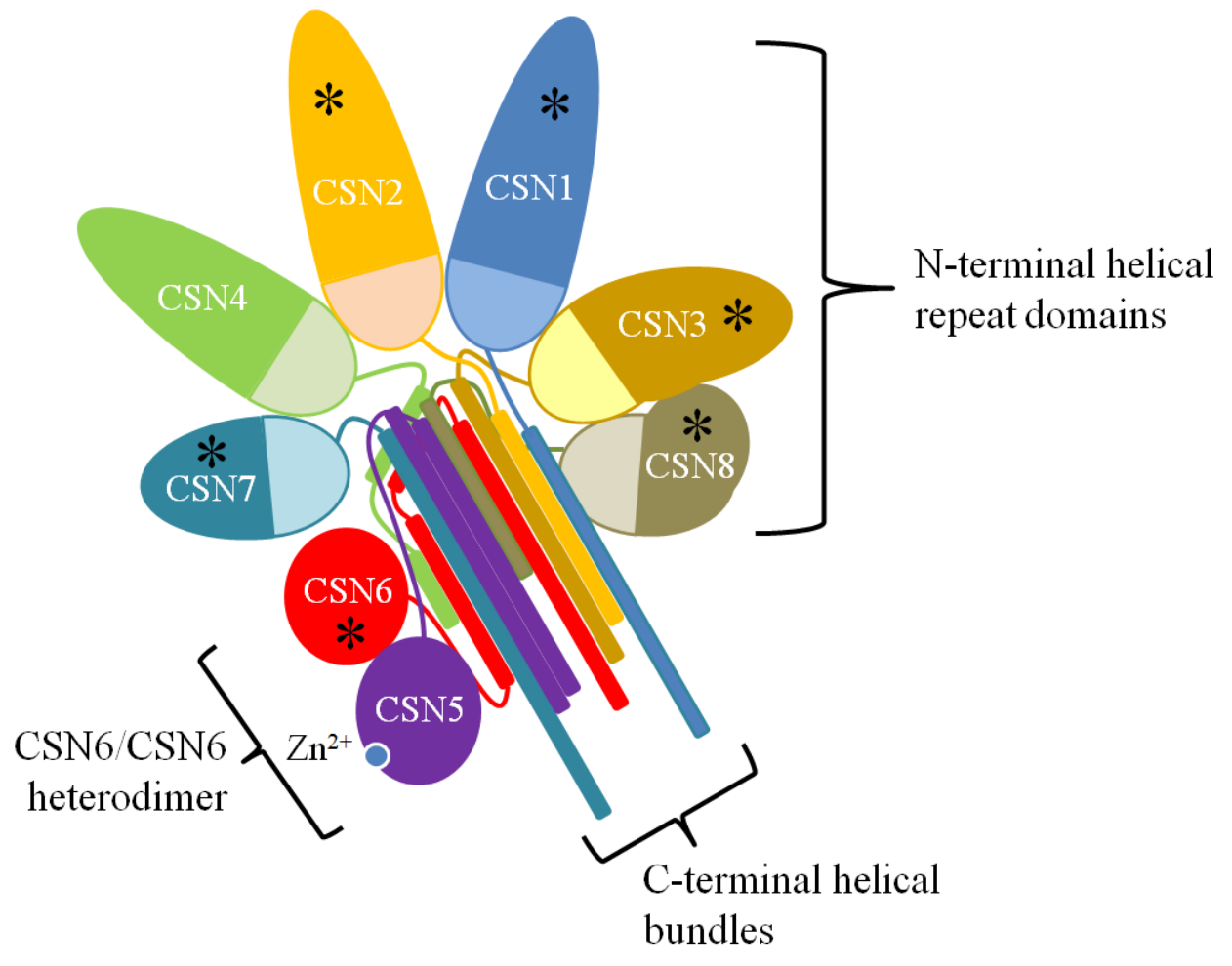

Figure 1. The CSN Structure. A two-dimensional schematic representation of the three-dimensional structure of the CSN as determined by Lingaraju et al [34]. The N-terminal repeat domains radiate out from the winged-helix domains of the PCI ring (lightly shaded half-circles). The C-terminal helical regions form a helical bundle that stabilizes the complex. The MPN domains of CSN5 and CSN6 rest on the helical bundle. Subunits reported as phosphorylation targets are marked with an asterisk $(*)$.

The CSN is catalytically active in both the nuclear and cytoplasmic fractions [40-44]. Additionally, a small fraction of CSN is bound to chromatin [37,45]. The CSN can be post-translationally modified, and, indeed, several subunits contain phosphorylation sites [17,20,37,46-51]. As a consequence, different cellular compartments can harbour different post-translationally modified CSN, and a great deal of work remains to understand the regulation of CSN subunits through their phosphorylation [37].

\subsection{Neddylation Cascade}

Neddylation is a form of reversible post-translational modification whereby the ubiquitin-like protein NEDD8 (neural precursor cell expressed, developmentally down-regulated 8) is conjugated to lysine residues in the target protein. Expression of the NEDD8 gene was initially identified to be downregulated during mouse brain development [52], and encodes an 81-amino acid protein that is 
$60 \%$ identical and $80 \%$ homologous to ubiquitin [53,54]. The neddylation pathway consists of E1, E2, and E3 enzymes, analogous to the ubiquitylation pathway (Figure 2). Precursor NEDD8 is processed at the C-terminal tail (Gly76) to its mature form by deneddylase 1 (DEN1), also known as NEDP1 or SENP8 [55-57], and by ubiquitin C-terminal hydrolase isozyme 3 (UCHL3) [58]. Matured NEDD8, with its C-terminal gly-gly motif, is conjugated to the NEDD8 E1 activating enzyme (NAE), a heterodimer composed of amyloid- $\beta$ precursor protein binding protein 1 (APPBP1, alternatively named NAE1) and ubiquitin-activating enzyme 3 (UBA3) [59,60]. NAE then transfers NEDD8 to an E2, which in metazoans are ubiquitin-conjugating enzyme E2F (UBE2F) and ubiquitin-conjugating enzyme E2M (UBE2M, also known as UBC12) [61,62]. UBE2F or UBE2M, with assistance from an E3, then transfers the NEDD8 onto the lysine of the target substrate.

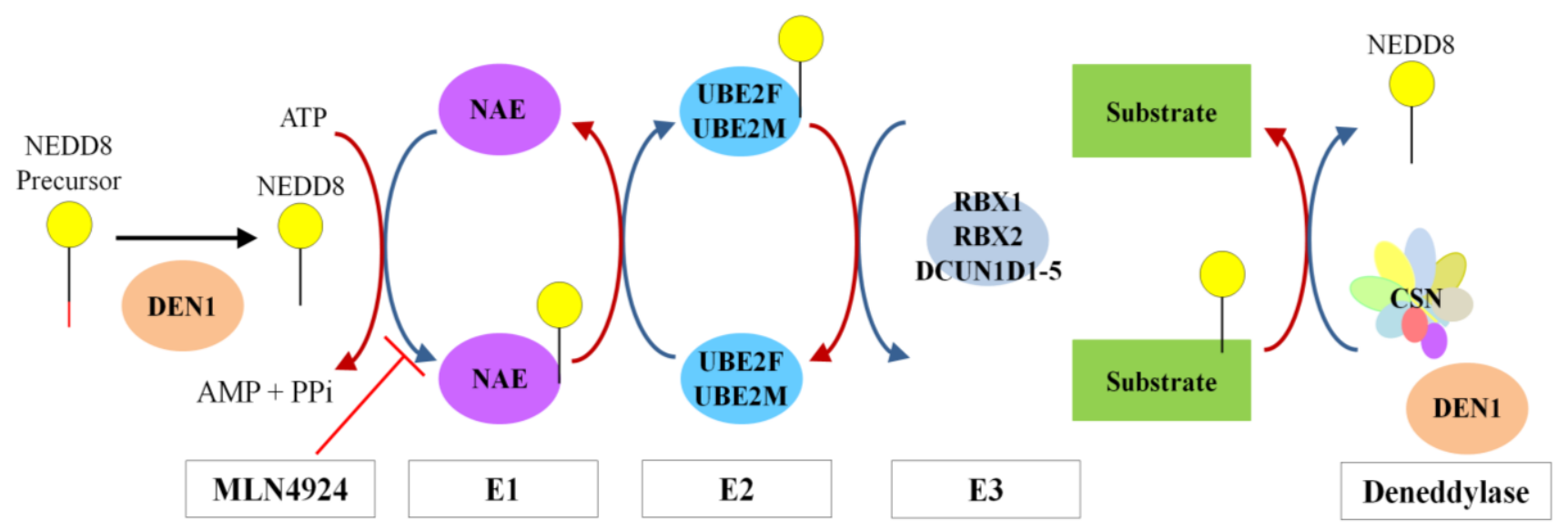

Figure 2. The Neddylation Cascade. A schematic representation of the main proteins in the neddylation cascade. Precursor NEDD8 is processed at the C-terminal to the activated form by DEN1. NEDD8 is conjugated to the target substrate through an E1 (NAE), and E2 (UBE2F or UBE2M), and an E3 (shown are RBX1/2, RNF111 and DCUN1D members). Deneddylation is achieved by the CSN and DEN1. The small molecule MLN4924 inhibits NAE, blocking the cascade.

Only a few E3s have been described to aid in neddylating targets. RING box protein 1 (RBX1, also known as ROC1) interacting with UBE2M, and RBX2 (ROC2) interacting with UBE2F, are E3s for cullin-RING ubiquitin ligases [16,63-65]. Neddylation E3 activity have also been described for ring finger protein 111 (RNF111-Arkadia) [66], and defective in cullin neddylation 1 domain containing (DCUN1D) proteins DCUN1D1-5 (SCCRO1-5) [67-71]. While DCUN1D1 is not essential for neddylation in vitro [72], DCUN1D1 knockouts are lethal in yeast and Caenorhabditis elegans [67]. However, this is not the case in mice, possibly due to compensation by other DCUN1D members [73]. Although it has been assumed that the DCUN1D proteins play similar roles in promoting neddylation, the case is not so clear for DCUN1D3 (SCCRO3). In one study, DCUN1D3 was shown to interact with UBE2M and promote cullin neddylation [70]. However, a later study found that DCUN1D3 does not have E3 activity and can inhibit DCUN1D1-mediated neddylation [73]. Additional proteins that exhibit NEDD8 E3 activity include murine double minute 2 (MDM2) [74], c-CBL [75,76], yeast Tfb3 [77], tripartite motif containing 40 (TRIM40) [78], and SMAD specific E3 ubiquitin protein ligase 1 (SMURF1) [79]. 
Although both the CSN and DEN1 can theoretically deneddylate a given protein substrate, they in fact do not have extensively overlapping protein targets $[26,55,80]$. DEN1 is more efficient in deconjugating hyperneddylated cullins in comparison to mono-neddylated CRLs in vitro, and DEN1 can deconjugate NEDD8 from non-cullin proteins in vivo in plants and humans [57,81]. On the other hand, the CSN appears restricted to deconjugating mono-neddylated substrates and is not efficient in processing precursor NEDD8 [57]. Recent evidence also indicates that the CSN can regulate human DEN1 and Aspergillus nidulans homolog DenA protein levels; however, the exact regulatory mechanism remains unknown [82]. Thus, the potential for cross-talk between these deneddylating enzymes should be carefully considered when interpreting CSN knock-down studies.

\subsection{Regulation of Cullins by the CSN}

The majority of proteins in the cell, including proteins in the DNA damage response, are targeted by different families of ubiquitin ligases. The multi-subunit cullin-RING ubiquitin ligases (CRLs) comprise the largest class of ligases [16]. The basic structure of the CRL consists of the cullin protein and the RING finger protein, which brings the substrate and substrate-specific adaptors in close proximity to the ubiquitin-carrying E2 protein; therefore, facilitating the transfer of ubiquitin onto the lysine residue on the target. CRLs are classed based on the cullin scaffold protein (CUL1-5, and CUL7), and specificity is defined by the cullin and a multitude of substrate adaptor proteins. (See [16,83] for additional background on CRLs). All cullins are modified by NEDD8 [84,85]. A more complex picture of the regulation of the CRL is emerging and a few regulatory mechanisms have been described thus far. As a result, this section will primarily discuss the role the CSN has on regulating CRLs.

Activation of the CRL is understood to be through the covalent attachment of NEDD8 to cullins, which as mentioned previously is mediated by RBX1 and DCUN1D1 members [64]. This causes a conformational change in the CRL architecture, promoting assembly, and enables substrate ubiquitylation [84]. For example, one study using CUL5 ${ }^{\mathrm{CTD}}$-RBX1 found that the neddylation led to a reorientation of the RING finger protein RBX1 [86]. Researchers have identified MLN4924 as a specific inhibitor of the E1 component APPBP1 (NAE1) [87]. This drug, which mimics the structure of AMP, forms an adduct with NEDD8 via NAE (Figure 2), blocking the neddylation cascade which leads to a reduction in neddylated CRLs and CRL substrate accumulation in cells [88]. This demonstrates that neddylation strongly regulates CRL-mediated ubquitylation and/or turnover of protein substrates.

The deneddylation of CRLs is achieved by the CSN, through its catalytic subunit CSN5. Initial understanding was that the CSN holoenzyme is transiently associated with the CRL to deneddylate cullins; however, a more complex picture of its role has begun to emerge. Structural analysis of the CSN-CRL association suggests that in vitro interaction with various cullins can further promote CSN5 activation [34,89]. The deneddylated cullin is a substrate for the protein CAND1 (cullin-associated NEDD8-dissociated protein 1), which regulates CRL activity by sequestering deneddylated cullins [90,91] (Figure 3). However, this interaction can be reversed depending on the levels of substrate adaptor proteins. CAND1 regulation was shown to only affect deneddylated CRLs, since adding CAND1 to assembled CRLs containing neddylated cullin blocked substrate adaptor dissociation [92]. The current belief is that that CAND1 promotes exchanging of the substrate adaptors in response to changing conditions in the cell [92-95]. It should be noted that CAND1 does not associate to the same degree 
with different cullin classes and may also display a preference to the exchange of particular substrate adaptors [95].
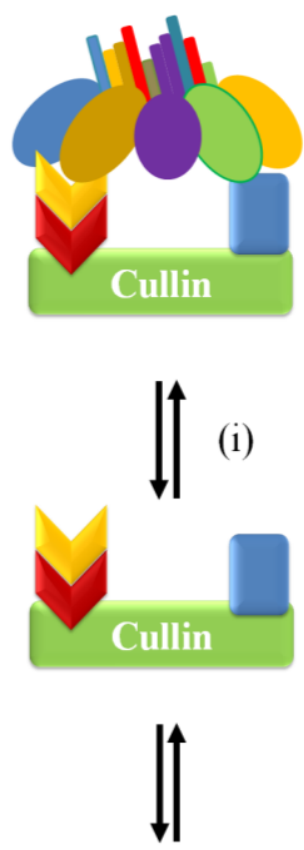

CAND1-mediated sequestration and substrate adaptor exchange
Deneddylation

(iv)

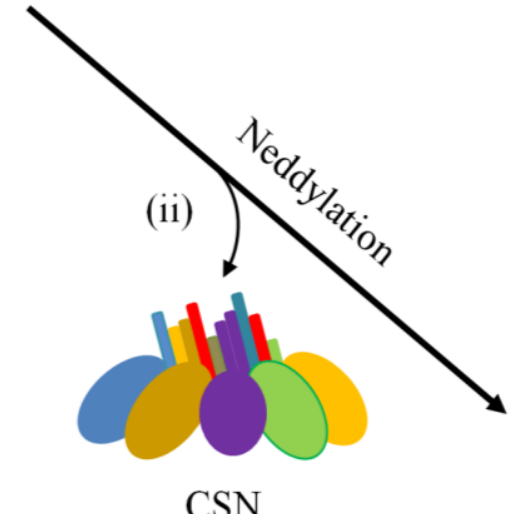

CSN

Displacement
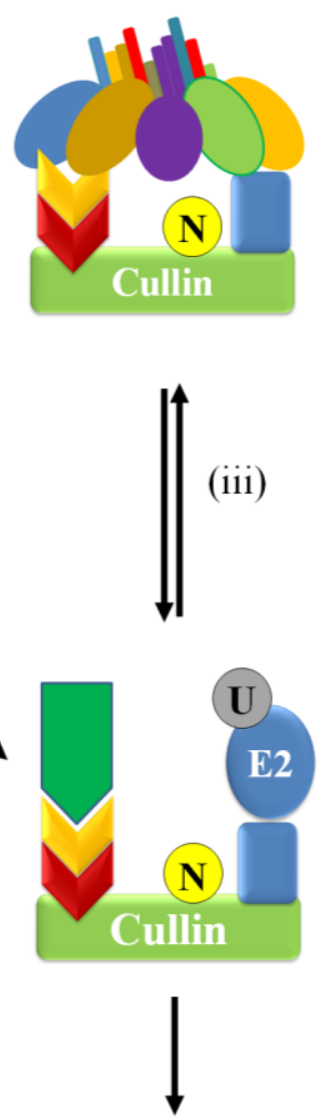

Substrate ubiquitylation

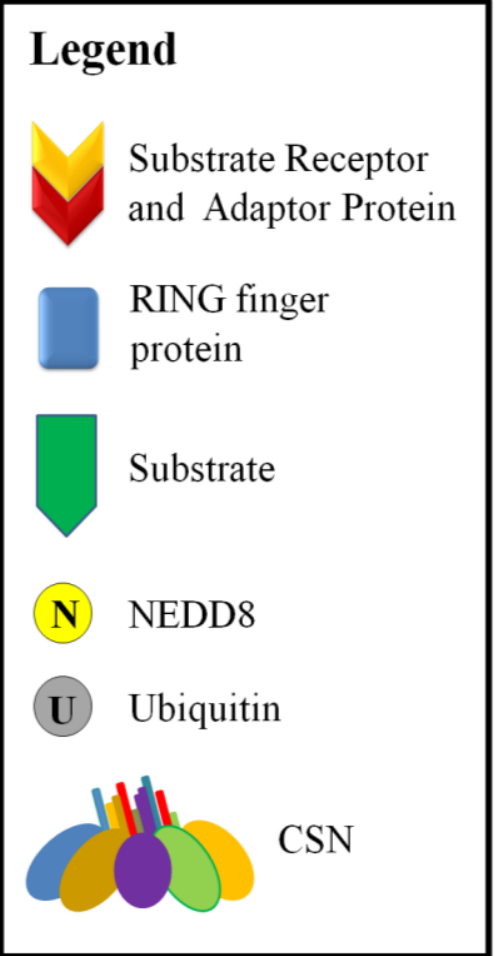

ubiquitylation

Figure 3. A schematic model for the neddylation-dependent regulation of CRLs by the CSN. The CSN can bind and inhibit substrate ubiquitylation in a neddylation dependent manner. Deneddylated CRLs can be a substrate for CAND1-mediated cullin sequestration and substrate adaptor exchange (i), but it can be activated through neddylation and CSN displacement to promote substrate and E2 binding and subsequent substrate ubiquitylation (ii). Interaction between the CRL to the CSN (iii and Figure 5) positions and activates CSN5 to allow deneddylation to occur (iv).

The CSN can also inhibit CRL activity independently of its deneddylase activity. The CSN can bind directly to CRLs and reduce ubiquitin ligase activity by sterically hindering interaction between the target substrate and the E2 (Figure 4) [89,96]. It appears that this mode of regulation can be influenced by the levels of substrate, which can compete with the CSN for the cullin [89,97]. This was demonstrated in one study where there was a reduction of CSN-CRL association when preincubated CSN-CRL was placed in the presence of substrate [89,96,97]. Additionally, global mass spectrometry studies on the cullin proteins found that on average only $10 \%-20 \%$ are associated with the CSN; whereas the association with substrate adaptors was dominant, suggesting that substrate adaptor availability is important in regulating CRLs [95]. The CSN is able to associate with the cullin in both neddylated and unneddylated states. In a study focusing on the cullin $1 \mathrm{CRL}, \mathrm{SCF}^{\mathrm{SKP} 2 / \mathrm{CKS} 1}, \mathrm{CSN} 2$ and CSN4 appear to 
be important in the interaction with the cullin and RING finger protein; whereas the other subunits, such as CSN1 and CSN3, are oriented toward the substrate adaptors (Figure 5) [34,89]. Association of the CSN to CRLs does not immediately lead to deneddylation. In a study that used o-ophenathroline to inhibit deneddylation after cell lysis, up to half the CSN-associated cullins were also neddylated [95]. This may indicate that an additional signal is required to allow isopeptidase cleavage or that the CSN is inhibited by some unknown factor, such as a CRL architecture that disfavors CSN-mediated deneddylation.

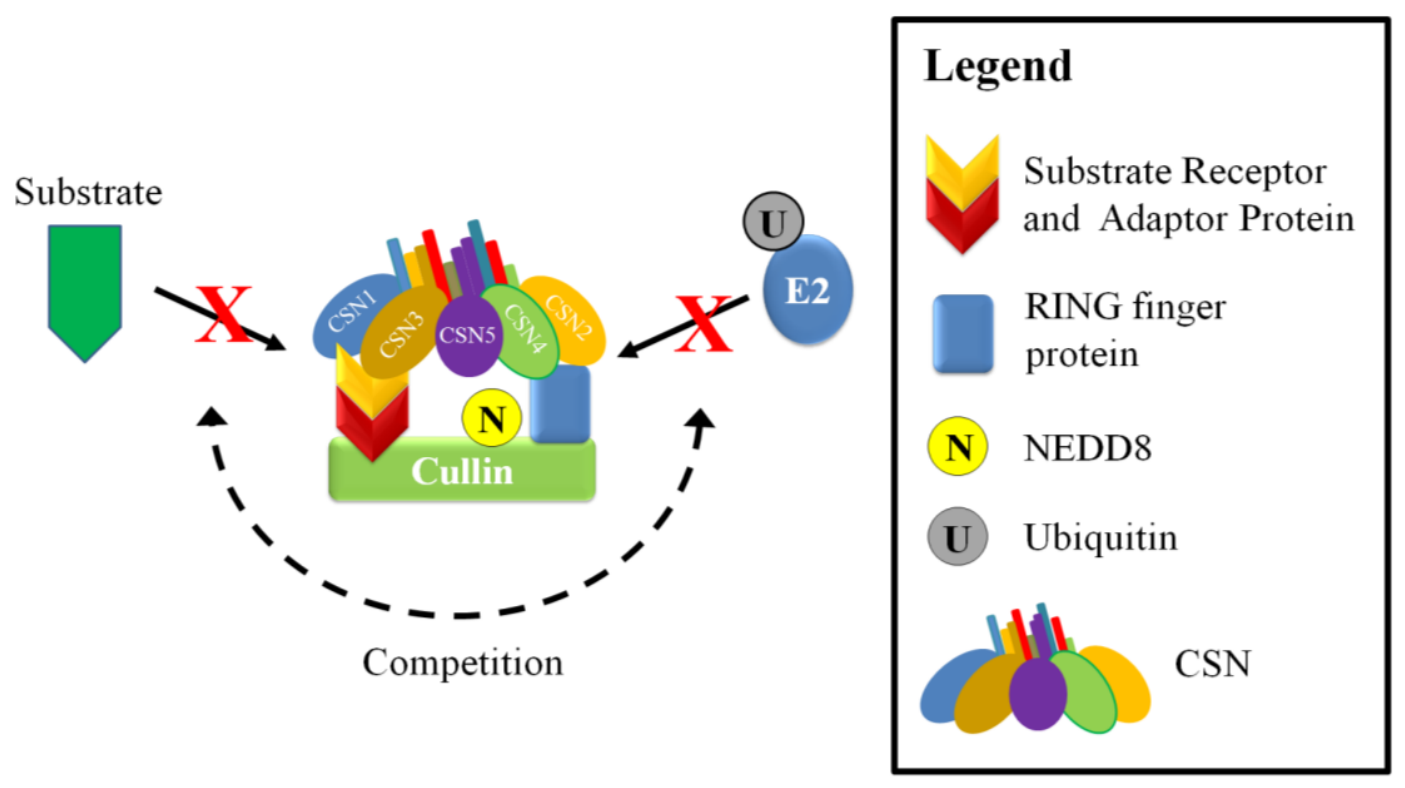

Figure 4. A schematic model of neddylation-independent regulation of CRLs by the CSN. The CSN interaction can inhibit CRLs in a neddylation independent manner by competing with substrates and ubiquitin-E2s for binding sites.
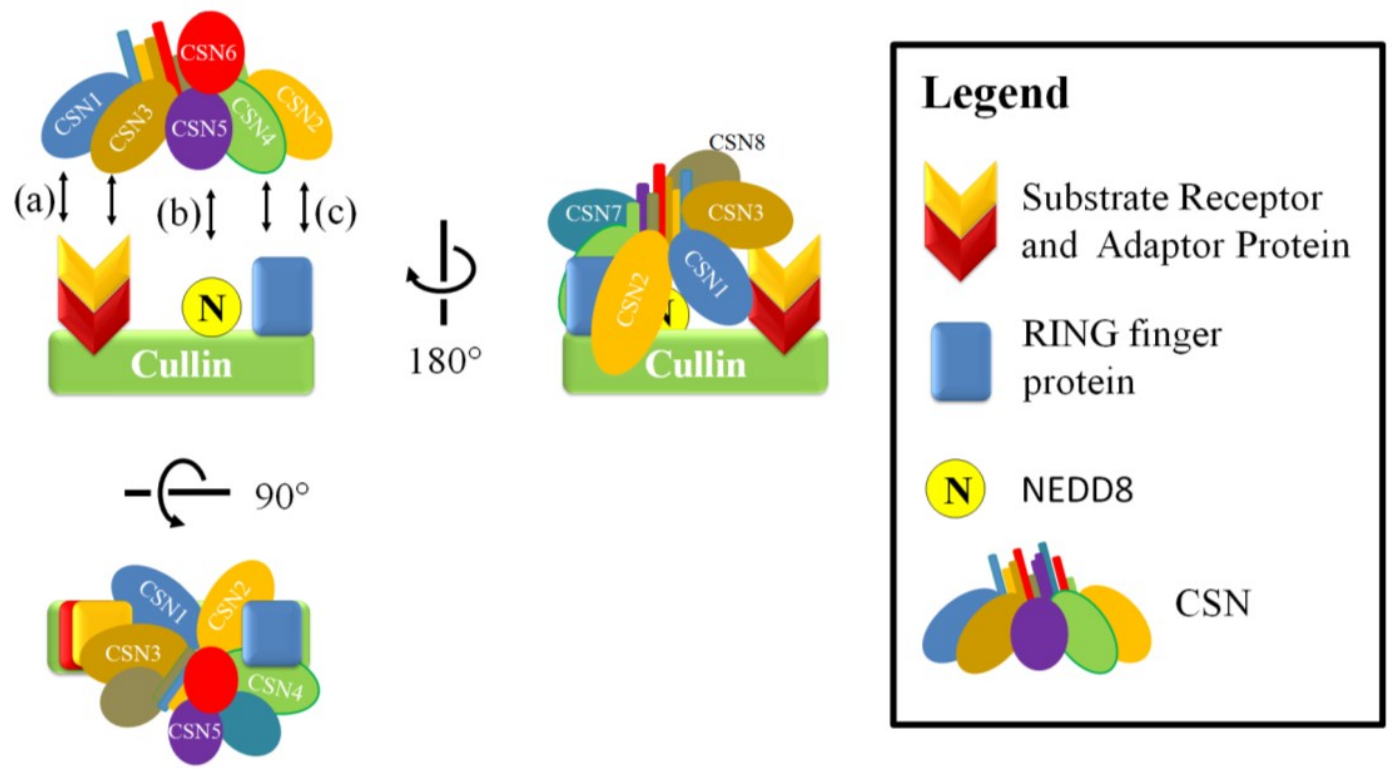

Figure 5. The CSN and CRL interaction. The CSN-CRL association involves the interaction of CSN1 and CSN3 on the substrate receptor (a) and CSN2 and CSN4 on the RING finger protein and the C-terminal portion of the cullin (c) $[34,89]$. These interactions position and activate CSN5 to allow deneddylation to occur (b). 
In addition to direct deneddylation, and steric hindrance, the CSN can associate with the de-ubiquitylating enzyme USP15. For example, in the fission yeast Schizosaccharomyces pombe, the CSN associates with USP15 homolog Ubp12p [98] to inhibit ubiquitylation of substrates and autoubiquitylation of CRL components [99]. Therefore, it is thought that ubiquitylation takes place after the CSN is displaced from the CRL complex.

\section{CSN and Neddylation in the DNA Damage Response}

\subsection{The DNA Damage Response}

Organisms have evolved complex systems that form the DNA damage response (DDR) to protect their genome from unwanted damage. These pathways sense and recognize different types of damage, and signal the activation of proteins for appropriate repair of DNA lesions. Since DNA damage comes in many forms, each type activates a unique repair response. Endogenous sources of DNA damage include hydrolysis (deamination, depurination, and depyrimidination), alkylation (6-O-Methylguanine) and oxidation (8-oxoG) by reactive oxygen species generated by respiration, and DNA mismatches during replication [100,101]. Exogenous sources of DNA damage include physical (ionizing radiation (IR), ultraviolet light (UV)) and chemical (such as chemotherapeutic drugs, and environmental carcinogens like industrial chemicals and tobacco smoke) [101]. The type of damage can be covalent modifications, single-strand and double-strand DNA breaks. In human cells, there are many forms of DNA repair, but not all of which have been associated with the CSN. However, nucleotide excision repair (NER) and double-strand break (DSB) repair have the most compelling data implicating the CSN in these mechanisms, which will be described in detail below.

Despite the form of DNA damage and specific repair mechanism involved, all have a defined hierarchy of protein recruitment. The initial response begins with the recruitment of proteins that recognize the damage or alteration to DNA ("sensors"), followed by those that receive the signal from the sensors and transmit it downstream ("mediators/transducers"), ultimately recruiting proteins that repair the lesion ("effectors"). Cytologically, these proteins form observable nuclear foci, and the number of foci corresponds to the degree of DNA damage [102]. Depending on the severity of the damage, a number of cellular changes occur including chromatin reorganization and alterations in transcription activity, and the activation of checkpoints to delay or stop cell cycle progression, senescence, and apoptosis [101]. Despite the many variations in the systems under the DDR umbrella, a common theme is the importance of ubiquitin and ubiquitin-like proteins and their corresponding E3 ubiquitin ligases. Many studies have characterized complex and overlapping modifications by ubiquitin-like proteins in damage sensing and mediating proteins as well as chromatin binding proteins [103]. This suggests that the CSN and neddylation could be important for regulating the DDR.

\subsection{The CSN and Neddylation in the DNA Damage Response}

In response to DNA damage, multiple processes such as cell cycle progression and checkpoint control are activated and involve the CSN and neddylation through CRLs [5,104]. For example, through ectopically expressing individual CSN subunits, it was found that CSN5 binds to the cyclin-dependent kinase inhibitor $\mathrm{p} 27^{\mathrm{Kip} 1}$ and targets it for ubiquitin-mediated proteasomal degradation in the G1 cell cycle 
phase [105]. This shuttling of $\mathrm{p} 27^{\mathrm{Kip} 1}$ from the nucleus to the cytoplasm could be mediated by additional interaction with CSN6 and the E3 ubiquitin ligase constitutive photomorphogenic 1 (COP1) [106]. Additionally, p27 degradation was observed from S to G2 phase, which involved p27 interaction with the CSN and CK2, and phosphorylation by CK2 [19]. Chromatin licensing and DNA replication factor 1 (CDT1), which is important for initiating DNA synthesis during S-phase in undamaged cells, is ubiquitylated by CRL4 [104]. The effect of neddylation in cell cycle regulation becomes apparent when cells are treated with MLN4924. These cells have altered S-phase progression in the cell cycle due to inhibition of CRL1 ${ }^{\mathrm{SKP} 2}$ and CRL4 ${ }^{\mathrm{CDT} 2}$, which stabilizes CDT1 leading to additional rounds of DNA replication in S phase cells [107]. Other CRL-regulated cell cycle proteins, including WEE1 and cyclin-dependent kinase 2 (CDK2), also accumulate in the presence of MLN4924 [108].

The CSN has a direct and indirect role in $\mathrm{p} 53$ regulation. The p53 protein is important for regulating cell fate in response to diverse cellular stress including DNA damage, which typically results in upregulation of p53 expression in response to genotoxic stress. Increased levels of p53 will, in turn, upregulate expression of the kinase inhibitor p21. Because $\mathrm{p} 21$ binds to CDK2 and inhibits its activity, the cell arrests at G1/S to prevent DNA replication until DNA damage is repaired [109]. In addition to activating cell cycle checkpoints, p53 regulates additional DDR responses such as senescence and apoptosis [110]. Early investigations found that specific phosphorylation of p53 on Threonine 155 promoted degradation through its interaction with MDM2. This phosphorylation appeared to be mediated by the p53 interaction with CSN5 in the holoenzyme [21,111]. In addition, MDM2 and CSN5 can regulate the export of $\mathrm{p} 53$ from the nucleus into the cytoplasm for degradation [112]. Similarly, it was found that over-expression of CSN6 can promote p53 degradation through inhibiting autoubiquitylation of MDM2, and mice that were heterozygous for CSN6 were more susceptible to DNA damage [113]. HER2-Akt signaling may also promote 533 degradation by promoting the stability of CSN6 in addition to phosphorylation and stabilization of MDM2 [51,114]. The p53 protein is also reported to be neddylated by MDM2 as well the SKP1-cullin-F-box (SCF) E3 ligase complex containing FBXO11 [74,115]. Currently, the biological role for p53 neddylation is not well characterized but is believed to impact p53 transcriptional activity $[74,115]$. The p53 gene (i.e., TP53) itself is also indirectly regulated via neddylation of the ribosomal protein L11, which is found in the nucleolus conjugated to NEDD8 in unstressed cells [116]. DNA damage is able to disrupt the nucleolus, which releases L11 into the nucleoplasm [117-119]. Nucleoplasmic L11 is then deneddylated, possibly by DEN1, which allow L11 to be recruited to the TP53 promoter [116,117]. The localization of L11 was also recently found to be regulated by the protein Myeloma overexpressed 2 (Myeov2). Myeov2 can sequester L11 in the nucleoplasm and promotes deneddylation of a host of proteins including L11, which in turn would impact TP53 gene expression [116]. Interestingly Myeov2 also interacts with the CSN holoenzyme via interaction with CSN5, and while this interaction does not appear to affect L11 neddylation in the experimental conditions used, it raises the possibility for a neddylation-dependent role in either nucleolar maintenance and/or TP53 gene regulation [116]. Finally, p53 transcriptional targets have also been shown to be regulated through neddylation. For example, the stability of the p53-regulated protein $14-3-3 \sigma$, a cell cycle regulator, appears to be regulated through interactions with CSN6 and COP1 [120]. 


\subsection{Nucleotide Excision Repair}

Helix-distorting forms of DNA damage are repaired by nucleotide excision repair (NER) [121]. Examples of these are cyclobutane pyrimidine dimers (CPDs) and pyrimidine 6-4 pyrimidone photoproducts (6-4PPs) created from ultraviolet (UV) radiation, and bulky adducts generated from environmental mutagens and chemotherapeutic drugs. There are two main types of NER: global genomic NER (GG-NER) that works on the whole genome, and transcription-coupled NER (TC-NER), which is restricted to actively transcribing genes. Impaired NER can contribute to genetic diseases. Two well-known hereditary photosensitivity diseases are Cockayne syndrome and xeroderma pigmantosum (XP). XP patients have an over 2000-fold increase risk of developing skin cancer because they cannot repair UV-induced lesions [122].

For GG-NER, mildly distorting lesions, such as CPDs and 6-4PPs, are most likely sensed by damaged DNA binding protein 2 (DDB2, also known as p48 or XPE), whereas larger distorting lesions are likely sensed by XPC-RAD23 [96,123,124] (see [121,125,126] for comprehensive reviews on the NER pathway). Briefly, after encountering a CPD or 6-4PP, CRL4 ${ }^{\mathrm{DDB} 2}$ ubiquitylates XPC. Binding of XPC allows other GG-NER proteins to be recruited to the site, such as transciption factor II Human (TFIIH). TFIIH, a multi-subunit complex with $3^{\prime}-5$ ' and 5'-3' helicase activity, is recruited to unwind the DNA at the damage site to form a repair bubble. XPC leaves and TFIIH recruits XPG, which incises the DNA backbone 3' to the lesion. XPA can interact with other NER proteins and is thought to coordinate the steps in NER, and replication protein A (RPA) positions XPC and XPF•ERCC1 (excision repair cross-complementation group 1) on the DNA [127]. XPF•ERCC1 binds to the complex and incises the DNA backbone 5' to the lesion. Several members of the complex and the cut oligonucleotide dissociate, and DNA synthesis proteins RFC (replication factor C)/PCNA (proliferating cell nuclear antigen) and DNA polymerase $\delta / \varepsilon$ fills in the gap that is then sealed by DNA ligase 1 .

TC-NER involves CSA (Cockayne syndrome WD repeat protein A, also known as ERCC8) and CSB (Cockayne syndrome protein B, also known as ERCC6) instead of XPC and DDB2 [128]. When the RNA polymerase encounters the lesion, it stalls, which is a damage recognition signal for repair. The stalled RNA polymerase II (RNAPII) then complexes with CSB to facilitate recruitment of NER components. Meanwhile, CSA forms an active complex with cullin 4 and DDB2 (CRL4 ${ }^{\mathrm{CSA}}$ ) [45]. Following the recruitment of NER components, such as TFIIH, RPA and XPA, repair proceeds in the same manner as described for GG-NER.

\subsection{Cullin 4 E3 Ubiquitin Ligase and NER}

Discussion of the role of the CSN and neddylation in NER requires a brief introduction to CRL4. The CRL4 architecture is composed of the scaffold protein cullin 4, RBX1, DDB1, and a family of substrate-specific receptor proteins termed DCAFs (Ddb1- and Cul4-associated factors) (Figure 6) [96]. Cullin 4 exists as two related forms in humans and other higher eukaryotes. Because of their high sequence identity, and that their respective CRL architectures are nearly identical, cullin 4A and cullin 4B share functional redundancy with limited exceptions [96,129]. Cullin 4 is involved in different aspects of the DNA damage response. Because untranscribed DNA is packaged more tightly into chromatin, the repair proteins have to gain access to (UV-induced) DNA damage sites. One approach 
is to modify histone proteins, and another is to remodel chromatin. Of note is the role of DDB2, which forms a heterodimer with DDB1 (p127) in the DDB complex. DDB1/2 associates with CRL4s to bring cullin 4 to chromatin after UV-mediated DNA damage. DDB2 probes the DNA strand for damage, and when detected it exposes, and stabilizes the CPD and 6-4PP lesions. Structural and molecular analysis indicates that this is mediated by the $\beta$-hairpin and WD40 domains within DDB2 [96,123]. Compared to XPC, DDB2 has a higher affinity for CPDs and 6-4PPs. This DNA interaction leads to CSN displacement, $\mathrm{CRL} 4{ }^{\mathrm{DDB} 2}$ reconfiguration, neddylation, and ligase activation, which allows the ubiquitylation of XPC, histones, and possibly other proteins in a zone surrounding the lesion $[123,124]$. DDB2 itself is a target of CRL4 [130,131] and ubiquitylated DDB2 is thought to allow dissociation from the repair site. CRL4 ${ }^{\mathrm{DDB} 2}$ ubiquitin ligases can also serve to ubiquitylate histones around the damage site in vitro to promote the recruitment of NER proteins such as XPA [132]; however, further studies are needed to fully understand its role [123]. In addition to affecting chromatin remodeling, XPC polyubiquitylation by CRL4 improves its stability and ability to bind to DNA, but so far the precise ubiquitylation site is unknown [124]. Instead, XPC eventually dissociates from the repair site to allow binding of downstream proteins. Recent investigations have revealed the possible role of an additional E3 ligase in this event. The SUMO-targeted ubiquitin ligase (STUbL) RNF111 ubiquitylates SUMOylated XPC at the residue K63 and is thought to promote dissociation from the damage site and association of downstream proteins XPG and ERCC1 [133-135]. In addition, polyubquitylated XPC is not immediately degraded by the $26 \mathrm{~S}$ proteasome because its association with RAD23, a protein with ubiquitin-associated (UBA) domains, inhibits its degradation until XPC has bound to damaged DNA [136-140].

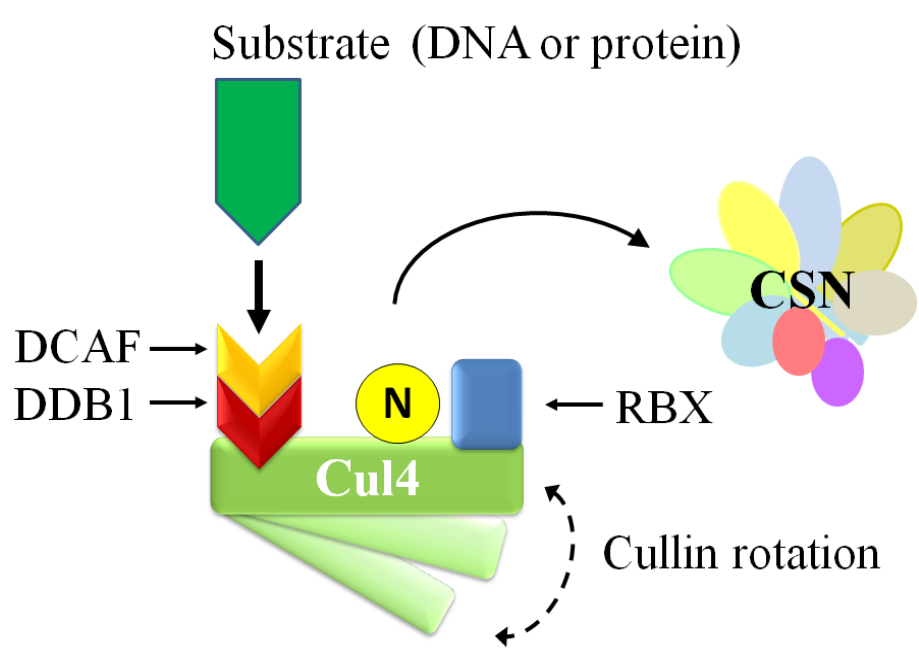

Figure 6. The architecture and activation of CRL4. The CRL4 architecture (adapted from Fischer et al. [96]) is composed of the scaffold protein cullin 4, RBX1, DDB1, and a family of substrate-specific receptor proteins termed DCAFs (Ddb1- and Cul4-associated factors), which DDB2 and CSA are members. Upon binding to CPDs or 6-4PPs on the DNA strand via DDB2, or a protein target (e.g., CSB via CSA), CRL4 undergoes a conformation change that promotes CSN displacement and neddylation to activate the ligase.

In TC-NER, cullin 4 forms an active complex with CSA and DDB2 (CRL4 ${ }^{\mathrm{CSA}}$ ) that is constitutively associatedd with chromatin [45]. The role of CRL4 ${ }^{\mathrm{CSA}}$ is to possibly ubiquitylate the stalled and 
hyperphosphorylated RNAPII [141,142]. CRL4 was found to target CSB for ubiquitylation and degradation several hours after UV irradiation in HeLa cells, suggesting a model where CRL4 is important for terminating the TC-NER response [130]. However, this was not observed in another study using a different cell line [131]. Other studies have also identified a UVSSA (UV-stimulated scaffold protein A)-mediated recruitment of the deubiquitylating enzyme ubiquitin-specific peptidase 7 (USP7), which can counteract CSB ubiquitylation [143,144]. Despite these recent insights, much remains to be uncovered about the role CRL4 plays in TC-NER.

\subsection{The CSN and NER}

The CSN regulates NER through CRL4 ${ }^{\mathrm{DDB} 2}$ and $\mathrm{CRL} 4{ }^{\mathrm{CSA}}$. CSN associates with $\mathrm{CRL} 4^{\mathrm{DDB} 2}$ to regulate it through deneddylation or accessibility of binding surfaces (Figure 7). In untreated cells, the CSN is associated with DDB2 complexes in the purified chromatin fraction. However, UV irradiation increases CRL4 neddylation and the association with CSN is no longer present in the chromatin fraction [45]. The question of what causes the CSN to dissociate from CRL4 ${ }^{\mathrm{DDB} 2}$ after UV damage was addressed Rao et al. [145], who found that it is facilitated by inositol hexakisphosphate kinase 1 (IP6K1). IP6K1 is an interacting partner with CSN1, CSN2 and DDB1, but is not targeted for degradation by CRL4. After UV damage, IP6K1 dissociates from CRL4 ${ }^{\mathrm{DDB} 2}$ and synthesizes the negatively-charged inositol pyrophosphate molecule IP7 that is thought to promote CSN dissociation. Additional changes to the CRL architecture could be required as the CSN can be displaced from $\mathrm{CRL}^{\mathrm{DDB} 2}$ and $\mathrm{CRL}^{\mathrm{CSA}}$ upon binding, in a neddylation independent manner [96,123]. After the CSN dissociates, neddylation of CRL4 occurs the ligase is activated. Over the course of repair after initial damage, CSN re-associates with the DDB complex, which suggests deactivation of CRL4 ${ }^{\mathrm{DDB} 2}$ [45]. The deactivation process for CRL4 is unclear; however, DDB2 is autoubiquitylated and degraded during its deactivation [124,146]. Conversely, higher levels of the CSN were associated with CSA after UV irradiation, indicating a different regulatory mechanism in TC-NER [45]. Taken together, it suggests that proper timing of CSN dissociation and association with CRL4 is important for functioning NER.

The interplay between the CSN and NER has only been partially elucidated and new insights may come from cellular studies of CSN subunit behaviour in vivo. For example, after treating mammalian cell lines with UV, Fuzesi-Levi and colleagues [37] noticed a dose-dependent temporal shuttling of fluorescence-tagged CSN subunits into the nucleus, which was reversed $4 \mathrm{~h}$ post-irradiation. Nucleoplasmic and chromatin-associated fractions contained increased levels of CSN protein, while the cytoplasmic fraction did not see a significant change after UV treatment. In addition, they also found that CSN subunits are phosphorylated early after post UV irradiation, and that the level of phosphorylation varies in each of the different cellular fractions. While the phosphorylation sites of CSN1, CSN3 and CSN8 have been mapped, it is not known how these phosphorylation events, or the shuttling of CSN subunits regulate the NER. 


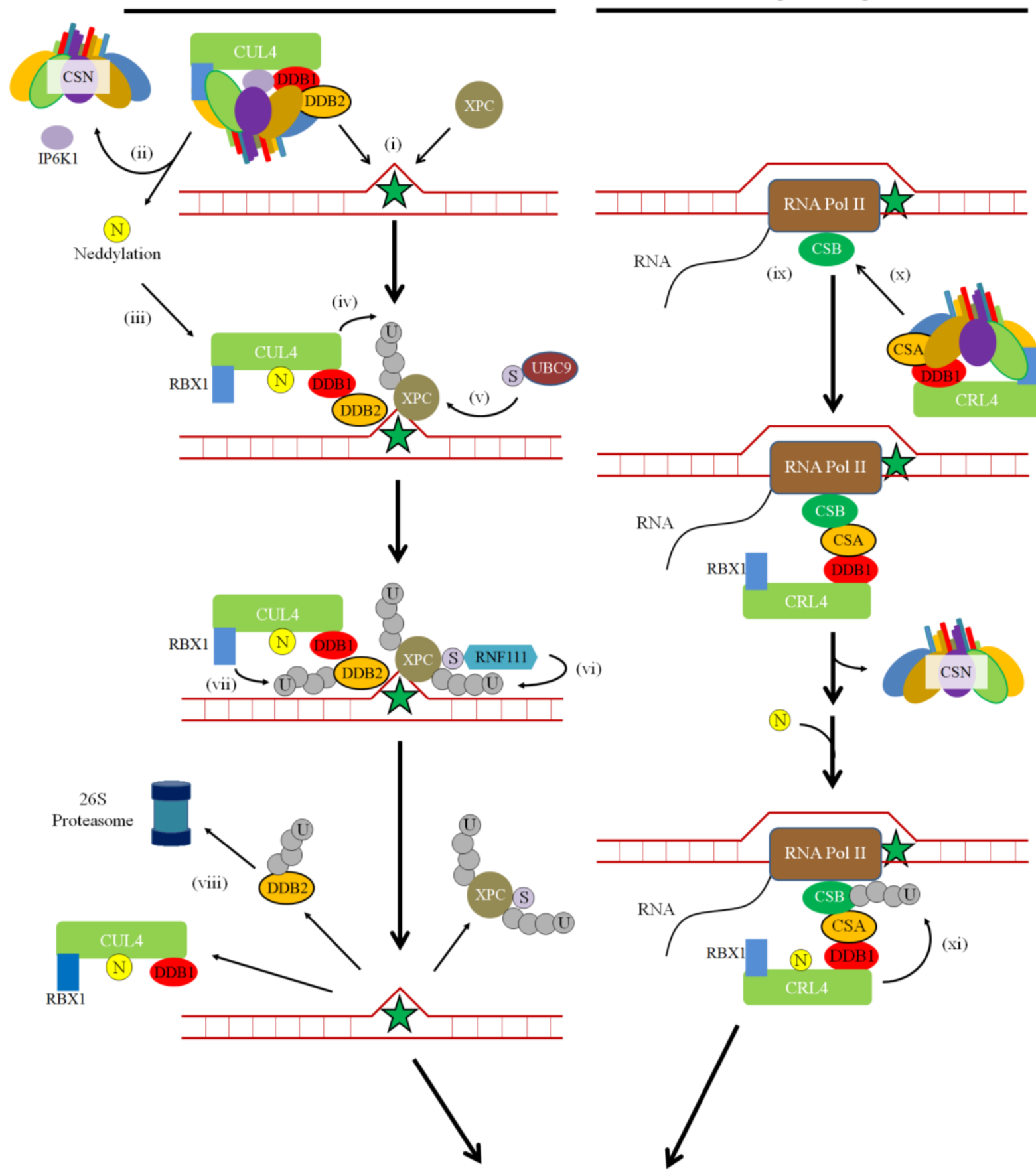

Damage verification, excision, DNA synthesis and ligation

Figure 7. The Role of the CSN and Neddylation in the Initial Steps of NER. Cells use nucleotide excision repair to remove bulky lesions on DNA. (A) In GG-NER, XPC-RAD23 or DDB1-DDB2 recognizes the lesions (indicated by the star) (i). The CSN dissociates from CRL4 with the assistance of IP6K1 (ii), which is thought to promote NEDD8 (N) conjugation and CRL4 activation (iii). DDB1-DDB2 forms a complex with CUL4 and RBX1 to ubiquitylate XPC, which recruit repair proteins involved in subsequent steps in GG-NER (iv). XPC is SUMOylated by UBC9 (v), which promote ubiquitylation at Lys63 by RNF111 (vi) and dissociation from the DNA. Additionally, CRL4-DDB1 ubiquitylates 
DDB2 (vii) to promote its degradation by the $26 \mathrm{~S}$ proteasome (viii). (B) In TC-NER, CSB associates to the stalled RNA Polymerase II (RNA Pol II) (ix). Through CSA, CRL4 is recruited to CSB (x). Following CSN dissociation and neddylation, CRL4 ${ }^{\mathrm{CSA}}$ possibly ubiquitylates CSB (xi). Both the GG-NER and TC-NER repair pathways then proceed with damage verification, damaged nucleotide excision, DNA synthesis, and ligation. $\mathrm{U}=$ Ubiquitin. $\mathrm{S}=\mathrm{SUMO}$ protein.

\subsection{DNA Double Strand Break Repair}

Ionizing radiation (IR, e.g., X-rays) and some chemotherapeutic drugs such as mitomycin C [147], and cisplatin [148] frequently cause DNA strand breaks. Cellular signaling in response to DNA double strand breaks (DSBs) is mediated by proteins in the phosphatidylinositol 3-kinase-like protein kinase family (PIKKs), which include ATM, ATR, and DNA-PK, and by proteins in the poly(ADP-ribose) polymerase (PARP) family[149]. DNA DSBs are repaired by mechanisms that fall under two broad categories: Non-homologous end-joining (NHEJ), and Homologous recombination (HR) (See [150-154] for comprehensive reviews of these pathways). NHEJ is characterized by the ligation of two DSB ends, and is generally considered mutagenic since little to no sequence homology is used for repair [155]. In some situations, there is $5^{\prime}$ to $3^{\prime}$ end resection, producing short $3^{\prime}$ end ssDNA overhangs. These overhangs can anneal to facilitate repair, termed microhomology-mediated end joining (MMEJ), also known as alternative NHEJ $[156,157]$. Conversely, HR is characterized by the use of long homologous sequences on the undamaged sister chromatid as a template to repair the broken strand, involves more significant end-processing and is less error-prone [158]. During HR, the exposed ssDNA is bound to and stabilized by RPA. Strand invasion of the homologous sequence in the sister chromatid by the ssDNA is then facilitated by RAD51 [159]. Several subtypes of HR have been described [152]. Furthermore, the requirement for an undamaged DNA template restricts HR to the S- and G2-phase of the cell cycle, whereas NHEJ can occur throughout the cell cycle [160,161].

Before a DNA DSB can be repaired, it must be detected, and more than one DSB sensor has been identified in human cells. One DSB sensor is the MRN complex, composed of meiotic recombination 11 (MRE11), RAD50 and nibrin (NBN), which has DNA binding, exonuclease, and endouclease activity [162-164]. MRN together with retinoblastoma binding protein 8 (RBBP8, also known as CtIP) stabilizes the DNA ends and promotes initial DNA end resection and HR [165,166]. Thus, CtIP via its role in end resection is thought to control HR as well as checkpoint signaling. Another DSB sensor is the Ku heterodimer formed by the binding of Ku70 (XRCC6) and Ku80 (XRCC5). Ku is a DNA-binding protein that quickly binds to free DNA ends and holds them in close proximity. $\mathrm{Ku}$ is important for recruiting proteins in NHEJ [151]. The PARP family members PARP1 and PARP2 are additional DNA damage sensors that recognize single-strand and double-strand DNA breaks, and initiates single-strand break repair and alternative NHEJ [167-169]. Why one sensor is preferentially recruited to a DSB site versus another (therefore promoting one repair pathway over another) is poorly understood and under intense study, but cell cycle status, nuclear position, and chromatin structure play important roles in repair pathway choice $[161,170,171]$.

As described briefly above, serine-threonine kinases of the PIKK family ATM, ataxia telangiectasic and Rad3 related (ATR), and DNA-PK potentiate the DNA damage signal throughout the cell to 
coordinate repair. ATM and DNA-PK primarily respond to DNA DSBs, the former through interacting with NBN in the MRN complex [172,173], and the latter through Ku-mediated DNA binding in NHEJ [174]. ATR is activated by the ssDNA binding protein RPA as a result of DNA end resection during DSB repair, or from replication stress [175]. PIKK members also phosphorylate effector proteins, which regulate cell cycle checkpoints, transcription, senescence, and apoptosis [175]. ATM phosphorylates and activates checkpoint kinase 2 (CHEK2; also known as CHK2), a known regulator of the G1/S checkpoint; while ATR targets the related checkpoint kinase 1 (CHEK1; also known as CHK1), a known regulator the intra-S and G2/M checkpoints [176].

Another feature found early in DSB repair is the phosphorylation of H2AX on serine $139(\gamma \mathrm{H} 2 \mathrm{AX})$. H2AX is phosphorylated by ATM in response to DSBs but is also targeted by ATR and DNA-PK $[177,178]$. $\gamma \mathrm{H} 2 \mathrm{AX}$ signaling is sustained by the recruitment of mediator of DNA damage checkpoint protein 1 (MDC1), which amplifies the phosphorylation signal and prevents $\mathrm{H} 2 \mathrm{AX}$ dephosphorylation [179]. $\gamma \mathrm{H} 2 \mathrm{AX}$ and $\mathrm{MDC} 1$ also recruit additional mediators to the site, such as tumor suppressor p53-binding protein 1 (53BP1), to the foci [175].

\subsection{Neddylation in DSB Repair}

A clear indication that neddylation is important for DSB repair is that inhibiting this pathway sensitizes cells to IR [180] and that NEDD8 localizes to DNA damage sites [66]. Preliminary studies suggest the possiblity that the STUbL E3 RNF111 interacts with UBE2M to neddylate targets such as histone H4 (H4) at DNA damage sites [66]. In addition, polyneddylated histone H4 is thought to be important for tethering of RNF168 to the DNA DSB site [66]. RNF168 can modify histone H2A as both a NEDD8 and ubiquitin E3 ligase, and its ubiquitinylase activity towards H2A is promoted by its neddylation and inhibited by NEDP1, which deneddylates RNF168 and inhibits its interaction with the ubiquitin E2 enzyme Ubc13 [181]. Neddylation of RNF168 regulates the downstream recruitment of BRCA1 following DNA damage by promoting H2A ubiquitination by RNF168 over H2A neddylation [181]. The degree of neddylation of chromatin and DDR proteins following DNA damage may also affect DNA repair pathway choice. RNF111-mediated neddylation, according to Jimeno et al. [158], inhibits DNA end resection involving the BRCA1 binding partner CtIP [165,182], therefore making HR less favourable. Gross inhibition of neddylation in the cell with the drug MLN4924, or knockdown of either RNF111 or UBE2M, promotes HR as evidenced by an increase in RPA foci in the nucleus. However, it should be noted that the STUbL activity of RNF111 ubiquitylates SUMOylated proteins, suggesting the role of RNF111 in the DDR is much more complex and may involves multiple UBL pathways $[133,183]$. What the neddylated targets of RNF111 are in this case will require additional studies. These studies generally suggest that neddylation inhibits DNA DSB repair by HR. This is perhaps an over simplification as there is also evidence that neddylation differentially affects HR sub-pathways. Specifically, MLN4924 treatment appears to promote singlestrand annealing (SSA), presumably by increasing DNA end resection, but inhibits HR by gene conversion [158]. Initial studies also suggest that neddylation could be important for terminating DNA repair. For examples, one study found that inhibiting neddylation with MLN4924 delayed the release of NHEJ factors, such as $\mathrm{Ku}$, from the break site after repair, possibly indicating that the dissolution of NHEJ factors from DNA breaks occurs through CRL-mediated ubiquitylation [184]. 


\subsection{CSN in DSB Repair}

The CSN appears be important for proper regulation of DNA double-strand break (DSB) repair response. Loss of CSN5 increased DSB defects and sensitized cells to DNA damage [185]. This is accompanied by increased $\gamma \mathrm{H} 2 \mathrm{AX}$, and activation of cell cycle checkpoint proteins. In addition, both ATM and ATR mediated effects are increased in response to CSN5 knockdown $[14,148]$. Since CSN5 harbours the deneddylase enzyme activity of the CSN complex, this data implies a possible role for deneddylation in DNA DSB repair. However, a non-catalytic role for free CSN5 cannot be fully discounted. There is also evidence that the CSN responds to DNA DSBs through changes in the localization and abundance of CSN subunits and/or coordination of the various repair pathways. For example, when HT29 cells were treated with different doses of the DNA damage agent mitomycin C, Feist et al. [47] noted a dose-dependent increase of CSN subunits. In addition, the CSN is recruited to DSB sites following IR, and the recruitment depends on neddylation [20,184]. Currently it is unknown if the entire CSN complex, subcomplexes or individual subunits are mediating specific events during DNA DSB repair. However, CSN8 can interact with ATM kinase directly, and CSN3 is phosphorylated on S410 by ATM in response to DNA damage [20]. Mutation of CSN3 (i.e., S401A) to prevent its phosphorylation by ATM can increase radiosensitivity but did not affect the recruitment of CSN3 to DNA DSBs. CSN3 phosphorylation is also required for efficient RAD51 repair foci formation, suggesting a role for CSN3 in end resection and possibly HR [20]. However, despite evidence for neddylation and/or CSN subunits in promoting HR [20,158], how the CSN might regulate DNA repair pathway choice between NHEJ and HR remains unclear. It has been speculated that repair pathway choice may depend on the degree of deneddylation following the initial round of neddylation [158]. Thus echoing the role of ubiquitinylation in DNA repair, it appears that both neddylation and deneddylation are required for the regulation of DNA DSB repair.

\section{Conclusions}

The DNA damage response (DDR) is tightly controlled by reversible protein post-translational modifications by ubiquitin-like (UBL) proteins including NEDD8. Neddylation is a primary regulator of cullin E3 ligase (CRL) activity, which target a number of DDR and cell cycle checkpoint proteins. The evidence that CRLs are transiently at the damage site raises the question of not only their role at the DNA break but also how there are regulated during the DDR. The CSN deneddylase complex is a major regulator of CRL activity, which we have discussed here in the context of the nucleotide excision repair (NER). However, this does not exclude possible roles for the CSN complex (or its subunits) outside of CRL regulation, particularly during DNA double-strand break (DSB) repair. Although an over simplification, neddylation appears to oppose DNA DSB repair by homologous recombination by affecting DNA end resection; however, the substrates of this neddylation and the details of this effect remain poorly characterized. Importantly, due to the intercommunication amongst ubiquitin and other UBL modification pathways including SUMOylation and neddylation, it will be increasingly important to consider crosstalk between these pathways in future studies.

While the CSN is a dynamic complex, not all the subunits have been studied in relation to DNA repair. Furthermore, the regulation of CSN subunits through their phosphorylation during the DDR and 
the ultimate impact these events have on both the progression of DNA repair and repair pathway choice is only beginning to be understood. In addition, the mechanism for shuttling the CSN to different cellular compartments also remains to be characterized and could be influenced by non-cullin interacting partners. A better understanding of the CSN and neddylation will not only provide a better understanding of the DDR but it may potentially have therapeutic implications for cancer treatment. Many tumors display defects in DDR, making them susceptible to DNA damaging agents [186]. However, some tumors adapt to DNA damage-inducing chemotherapeutic drugs, such as cisplatin, by enhancing DDR activity, precipitating the need for DDR inhibitors [187]. In some human cancers, elevated expression levels of CSN5 and CSN6 are correlated with cancer progression and poor prognosis [148,188-191], which may be due to increased DDR function reducing the efficacy of cytotoxic therapies employing DNA damaging agents. Given that both the CSN and neddylation appear to have a significant regulatory function in the DDR, we predict that the CSN will be an increasingly attractive drug target for the development of chemotherapy and radiosensitization agents to treat cancer.

\section{Acknowledgments}

This work is funded by an operating grant to Graham Dellaire from the Canadian Institutes of Health Research (CIHR) (MOP-84260). Dudley Chung is funded by the Nova Scotia Graduate Studentship and Graham Dellaire is a Senior Scientist of the Beatrice Hunter Cancer Research Institute (BHCRI). Special thanks to Livia Anthes for critical reading and feedback of this manuscript.

\section{Author Contributions}

Dudley Chung and Graham Dellaire contributed to preparing this manuscript.

\section{Conflicts of Interest}

The authors declare no conflict of interest.

\section{References}

1. Wei, N.; Chamovitz, D.A.; Deng, X.W. Arabidopsis COP9 is a component of a novel signaling complex mediating light control of development. Cell 1994, 78, 117-124.

2. Seeger, M.; Kraft, R.; Ferrell, K.; Bech-Otschir, D.; Dumdey, R.; Schade, R.; Gordon, C.; Naumann, M.; Dubiel, W. A novel protein complex involved in signal transduction possessing similarities to $26 \mathrm{~S}$ proteasome subunits. FASEB J. 1998, 12, 469-478.

3. Freilich, S.; Oron, E.; Kapp, Y.; Nevo-Caspi, Y.; Orgad, S.; Segal, D.; Chamovitz, D.A. The COP9 signalosome is essential for development of Drosophila melanogaster. Curr. Biol. 1999, 9 , 1187-1190.

4. Wei, N.; Deng, X.W. Characterization and purification of the mammalian COP9 complex, a conserved nuclear regulator initially identified as a repressor of photomorphogenesis in higher plants. Photochem. Photobiol. 1998, 68, 237-241. 
5. Mundt, K.E.; Porte, J.; Murray, J.M.; Brikos, C.; Christensen, P.U.; Caspari, T.; Hagan, I.M.; Millar, J.B.; Simanis, V.; Hofmann, K.; et al. The COP9/signalosome complex is conserved in fission yeast and has a role in S phase. Curr. Biol. 1999, 9, 1427-1430.

6. Maytal-Kivity, V.; Pick, E.; Piran, R.; Hofmann, K.; Glickman, M.H. The COP9 signalosome-like complex in S. cerevisiae and links to other PCI complexes. Int. J. Biochem. Cell Biol. 2003, 35, 706-715.

7. Rajan, K.E.; Rajkumar, R.; Liao, C.C.; Ganesh, A.; Marimuthu, G. Light-induced COP9 signalosome expression in the Indian false vampire bat Megaderma lyra. J. Physiol. Sci. 2010, 60, 43-49.

8. Wee, S.; Hetfeld, B.; Dubiel, W.; Wolf, D.A. Conservation of the COP9/signalosome in budding yeast. BMC Genet. 2002, doi:10.1186/1471-2156-3-15.

9. Lima, J.F.; Malavazi, I.; von Zeska Kress Fagundes, M.R.; Savoldi, M.; Goldman, M.H.; Schwier, E.; Braus, G.H.; Goldman, G.H. The CSND/CSNE signalosome genes are involved in the Aspergillus nidulans DNA damage response. Genetics 2005, 171, 1003-1015.

10. Wei, N.; Serino, G.; Deng, X.W. The COP9 signalosome: More than a protease. Trends Biochem. Sci. 2008, 33, 592-600.

11. Oron, E.; Mannervik, M.; Rencus, S.; Harari-Steinberg, O.; Neuman-Silberberg, S.; Segal, D.; Chamovitz, D.A. COP9 signalosome subunits 4 and 5 regulate multiple pleiotropic pathways in Drosophila melanogaster. Development 2002, 129, 4399-4409.

12. Lykke-Andersen, K.; Schaefer, L.; Menon, S.; Deng, X.W.; Miller, J.B.; Wei, N. Disruption of the COP9 signalosome CSN2 subunit in mice causes deficient cell proliferation, accumulation of p53 and cyclin E, and early embryonic death. Mol. Cell. Biol. 2003, 23, 6790-6797.

13. Rosel, D.; Kimmel, A.R. The COP9 signalosome regulates cell proliferation of Dictyostelium discoideum. Eur. J. Cell Biol. 2006, 85, 1023-1034.

14. Panattoni, M.; Maiorino, L.; Lukacs, A.; Zentilin, L.; Mazza, D.; Sanvito, F.; Sitia, G.; Guidotti, L.G.; Pardi, R. The COP9 signalosome is a repressor of replicative stress responses and polyploidization in the regenerating liver. Hepatology 2014, 59, 2331-2343.

15. Lyapina, S.; Cope, G.; Shevchenko, A.; Serino, G.; Tsuge, T.; Zhou, C.; Wolf, D.A.; Wei, N.; Shevchenko, A.; Deshaies, R.J. Promotion of NEDD-CUL1 conjugate cleavage by COP9 signalosome. Science 2001, 292, 1382-1385.

16. Petroski, M.D.; Deshaies, R.J. Function and regulation of cullin-RING ubiquitin ligases. Nat. Rev. Mol. Cell Biol. 2005, 6, 9-20.

17. Henke, W.; Ferrell, K.; Bech-Otschir, D.; Seeger, M.; Schade, R.; Jungblut, P.; Naumann, M.; Dubiel, W. Comparison of human COP9 signalsome and 26S proteasome 'lid'. Mol. Biol. Rep. 1999, 26, 29-34.

18. Uhle, S.; Medalia, O.; Waldron, R.; Dumdey, R.; Henklein, P.; Bech-Otschir, D.; Huang, X.; Berse, M.; Sperling, J.; Schade, R.; et al. Protein kinase CK2 and protein kinase D are associated with the COP9 signalosome. EMBO J. 2003, 22, 1302-1312.

19. Huang, X.; Wagner, E.; Dumdey, R.; Peth, A.; Berse, M.; Dubiel, W.; Berndt, C. Phosphorylation by COP9 signalosome-associated CK2 promotes degradation of p27 during the G1 cell cycle phase. Isr. J. Chem. 2006, 46, 231-238. 
20. Meir, M.; Galanty, Y.; Kashani, L.; Blank, M.; Khosravi, R.; Fernandez-Avila, M.J.; Cruz-Garcia, A.; Star, A.; Shochot, L.; Thomas, Y.; et al. The COP9 signalosome is vital for timely repair of DNA double-strand breaks. Nucleic Acids Res. 2015, 43, 4517-4530.

21. Sun, Y.; Wilson, M.P.; Majerus, P.W. Inositol 1,3,4-trisphosphate 5/6-kinase associates with the COP9 signalosome by binding to CSN1. J. Biol. Chem. 2002, 277, 45759-45764.

22. Glickman, M.H.; Rubin, D.M.; Coux, O.; Wefes, I.; Pfeifer, G.; Cjeka, Z.; Baumeister, W.; Fried, V.A.; Finley, D. A subcomplex of the proteasome regulatory particle required for ubiquitin-conjugate degradation and related to the COP9-signalosome and eIF3. Cell 1998, 94, $615-623$.

23. Kwok, S.F.; Staub, J.M.; Deng, X.W. Characterization of two subunits of Arabidopsis 19S proteasome regulatory complex and its possible interaction with the COP9 complex. J. Mol. Biol. 1999, 285, 85-95.

24. Yahalom, A.; Kim, T.H.; Winter, E.; Karniol, B.; von Arnim, A.G.; Chamovitz, D.A. Arabidopsis eIF3e (INT-6) associates with both eIF3c and the COP9 signalosome subunit CSN7. J. Biol. Chem. 2001, 276, 334-340.

25. Claret, F.X.; Hibi, M.; Dhut, S.; Toda, T.; Karin, M. A new group of conserved coactivators that increase the specificity of AP-1 transcription factors. Nature 1996, 383, 453-457.

26. Cope, G.A.; Suh, G.S.; Aravind, L.; Schwarz, S.E.; Zipursky, S.L.; Koonin, E.V.; Deshaies, R.J. Role of predicted metalloprotease motif of Jab1/CSN5 in cleavage of Nedd8 from Cul1. Science 2002, 298, 608-611.

27. Olma, M.H.; Roy, M.; Le Bihan, T.; Sumara, I.; Maerki, S.; Larsen, B.; Quadroni, M.; Peter, M.; Tyers, M.; Pintard, L. An interaction network of the mammalian COP9 signalosome identifies Dda1 as a core subunit of multiple Cul4-based E3 ligases. J. Cell Sci. 2009, 122, 1035-1044.

28. Kapelari, B.; Bech-Otschir, D.; Hegerl, R.; Schade, R.; Dumdey, R.; Dubiel, W. Electron microscopy and subunit-subunit interaction studies reveal a first architecture of COP9 signalosome. J. Mol. Biol. 2000, 300, 1169-1178.

29. Sharon, M.; Mao, H.; Boeri Erba, E.; Stephens, E.; Zheng, N.; Robinson, C.V. Symmetrical modularity of the COP9 signalosome complex suggests its multifunctionality. Structure 2009, 17, 31-40.

30. Enchev, R.I.; Schreiber, A.; Beuron, F.; Morris, E.P. Structural insights into the COP9 signalosome and its common architecture with the $26 \mathrm{~S}$ proteasome lid and eIF3. Structure 2010, 18, 518-527.

31. Kotiguda, G.G.; Weinberg, D.; Dessau, M.; Salvi, C.; Serino, G.; Chamovitz, D.A.; Hirsch, J.A. The organization of a CSN5-containing subcomplex of the COP9 signalosome. J. Biol. Chem. 2012, 287, 42031-42041.

32. Lee, J.H.; Yi, L.; Li, J.; Schweitzer, K.; Borgmann, M.; Naumann, M.; Wu, H. Crystal structure and versatile functional roles of the COP9 signalosome subunit 1. Proc. Natl. Acad. Sci. USA 2013, 110, 11845-11850.

33. Rockel, B.; Schmaler, T.; Huang, X.; Dubiel, W. Electron microscopy and in vitro deneddylation reveal similar architectures and biochemistry of isolated human and Flag-mouse COP9 signalosome complexes. Biochem. Biophys. Res. Commun. 2014, 450, 991-997.

34. Lingaraju, G.M.; Bunker, R.D.; Cavadini, S.; Hess, D.; Hassiepen, U.; Renatus, M.; Fischer, E.S.; Thoma, N.H. Crystal structure of the human COP9 signalosome. Nature 2014, 512, 161-165. 
35. Birol, M.; Enchev, R.I.; Padilla, A.; Stengel, F.; Aebersold, R.; Betzi, S.; Yang, Y.; Hoh, F.; Peter, M.; Dumas, C.; et al. Structural and biochemical characterization of the Cop9 signalosome CSN5/CSN6 heterodimer. PLoS ONE 2014, doi:10.1371/journal.pone.0105688.

36. Echalier, A.; Pan, Y.; Birol, M.; Tavernier, N.; Pintard, L.; Hoh, F.; Ebel, C.; Galophe, N.; Claret, F.X.; Dumas, C. Insights into the regulation of the human COP9 signalosome catalytic subunit, CSN5/Jab1. Proc. Natl. Acad. Sci. USA 2013, 110, 1273-1278.

37. Fuzesi-Levi, M.G.; Ben-Nissan, G.; Bianchi, E.; Zhou, H.; Deery, M.J.; Lilley, K.S.; Levin, Y.; Sharon, M. Dynamic regulation of the COP9 signalosome in response to DNA damage. Mol. Cell. Biol. 2014, 34, 1066-1076.

38. Yoshida, A.; Yoneda-Kato, N.; Kato, J.Y. CSN5 specifically interacts with CDK2 and controls senescence in a cytoplasmic cyclin E-mediated manner. Sci. Rep. 2013, doi:10.1038/srep01054.

39. Liu, C.; Guo, L.Q.; Menon, S.; Jin, D.; Pick, E.; Wang, X.; Deng, X.W.; Wei, N. COP9 signalosome subunit CSN8 is involved in maintaining proper duration of the G1 phase. J. Biol. Chem. 2013, 288, 20443-20452.

40. Mundt, K.E.; Liu, C.; Carr, A.M. Deletion mutants in COP9/signalosome subunits in fission yeast Schizosaccharomyces pombe display distinct phenotypes. Mol. Biol. Cell 2002, 13, 493-502.

41. Chamovitz, D.A.; Wei, N.; Osterlund, M.T.; von Arnim, A.G.; Staub, J.M.; Matsui, M.; Deng, X.W. The COP9 complex, a novel multisubunit nuclear regulator involved in light control of a plant developmental switch. Cell 1996, 86, 115-121.

42. Huang, J.; Yuan, H.; Lu, C.; Liu, X.; Cao, X.; Wan, M. Jab1 mediates protein degradation of the Rad9-Rad1-Hus1 checkpoint complex. J. Mol. Biol. 2007, 371, 514-527.

43. Hunter, C.; Evans, J.; Valencik, M.L. Subunit 3 of the COP9 signalosome is poised to facilitate communication between the extracellular matrix and the nucleus through the muscle-specific beta1D integrin. Cell Commun. Adhes. 2008, 15, 247-260.

44. Wang, J.; Barnes, R.O.; West, N.R.; Olson, M.; Chu, J.E.; Watson, P.H. Jab1 is a target of EGFR signaling in ER $\alpha$-negative breast cancer. Breast Cancer Res. 2008, doi:10.1186/bcr2105.

45. Groisman, R.; Polanowska, J.; Kuraoka, I.; Sawada, J.; Saijo, M.; Drapkin, R.; Kisselev, A.F.; Tanaka, K.; Nakatani, Y. The ubiquitin ligase activity in the DDB2 and CSA complexes is differentially regulated by the COP9 signalosome in response to DNA damage. Cell 2003, 113, $357-367$.

46. Huang, X.; Langelotz, C.; Hetfeld-Pechoc, B.K.; Schwenk, W.; Dubiel, W. The COP9 signalosome mediates $\beta$-catenin degradation by deneddylation and blocks adenomatous polyposis coli destruction via USP15. J. Mol. Biol. 2009, 391, 691-702.

47. Feist, M.; Huang, X.; Muller, J.M.; Rau, B.; Dubiel, W. Can hyperthermic intraperitoneal chemotherapy efficiency be improved by blocking the DNA repair factor COP9 signalosome? Int. J. Colorectal Dis. 2014, 29, 673-680.

48. Shiloh, Y. The ATM-mediated DNA-damage response: Taking shape. Trends Biochem. Sci. 2006, 31, 402-410.

49. Olsen, J.V.; Vermeulen, M.; Santamaria, A.; Kumar, C.; Miller, M.L.; Jensen, L.J.; Gnad, F.; Cox, J.; Jensen, T.S.; Nigg, E.A.; et al. Quantitative phosphoproteomics reveals widespread full phosphorylation site occupancy during mitosis. Sci. Signal. 2010, doi:10.1126/scisignal.2000475. 
50. Matsuoka, S.; Ballif, B.A.; Smogorzewska, A.; McDonald, E.R., 3rd; Hurov, K.E.; Luo, J.; Bakalarski, C.E.; Zhao, Z.; Solimini, N.; Lerenthal, Y.; et al. ATM and ATR substrate analysis reveals extensive protein networks responsive to DNA damage. Science 2007, 316, 1160-1166.

51. Xue, Y.; Chen, J.; Choi, H.H.; Phan, L.; Chou, P.C.; Zhao, R.; Yang, H.; Santiago, J.; Liu, M.; Yeung, G.E.; et al. HER2-Akt signaling in regulating COP9 signalsome subunit 6 and p53. Cell Cycle 2012, 11, 4181-4190.

52. Kumar, S.; Tomooka, Y.; Noda, M. Identification of a set of genes with developmentally down-regulated expression in the mouse brain. Biochem. Biophys. Res. Commun. 1992, 185, $1155-1161$.

53. Kumar, S.; Yoshida, Y.; Noda, M. Cloning of a cDNA which encodes a novel ubiquitin-like protein. Biochem. Biophys. Res. Commun. 1993, 195, 393-399.

54. Kamitani, T.; Kito, K.; Nguyen, H.P.; Yeh, E.T. Characterization of NEDD8, a developmentally down-regulated ubiquitin-like protein. J. Biol. Chem. 1997, 272, 28557-28562.

55. Chan, Y.; Yoon, J.; Wu, J.T.; Kim, H.J.; Pan, K.T.; Yim, J.; Chien, C.T. DEN1 deneddylates non-cullin proteins in vivo. J. Cell Sci. 2008, 121, 3218-3223.

56. Mendoza, H.M.; Shen, L.N.; Botting, C.; Lewis, A.; Chen, J.; Ink, B.; Hay, R.T. NEDP1, a highly conserved cysteine protease that deNEDDylates Cullins. J. Biol. Chem. 2003, 278, 25637-25643.

57. Wu, K.; Yamoah, K.; Dolios, G.; Gan-Erdene, T.; Tan, P.; Chen, A.; Lee, C.G.; Wei, N.; Wilkinson, K.D.; Wang, R.; et al. DEN1 is a dual function protease capable of processing the C terminus of Nedd8 and deconjugating hyper-neddylated CUL1. J. Biol. Chem. 2003, 278, 28882-28891.

58. Wada, H.; Kito, K.; Caskey, L.S.; Yeh, E.T.; Kamitani, T. Cleavage of the C-terminus of NEDD8 by UCH-L3. Biochem. Biophys. Res. Commun. 1998, 251, 688-692.

59. Walden, H.; Podgorski, M.S.; Huang, D.T.; Miller, D.W.; Howard, R.J.; Minor, D.L., Jr.; Holton, J.M.; Schulman, B.A. The structure of the APPBP1-UBA3-NEDD8-ATP complex reveals the basis for selective ubiquitin-like protein activation by an E1. Mol. Cell 2003, 12, 1427-1437.

60. Bohnsack, R.N.; Haas, A.L. Conservation in the mechanism of Nedd8 activation by the human AppBp1-Uba3 heterodimer. J. Biol. Chem. 2003, 278, 26823-26830.

61. Gong, L.; Yeh, E.T. Identification of the activating and conjugating enzymes of the NEDD8 conjugation pathway. J. Biol. Chem. 1999, 274, 12036-12042.

62. Osaka, F.; Kawasaki, H.; Aida, N.; Saeki, M.; Chiba, T.; Kawashima, S.; Tanaka, K.; Kato, S. A new NEDD8-ligating system for cullin-4A. Genes Dev. 1998, 12, 2263-2268.

63. Huang, D.T.; Ayrault, O.; Hunt, H.W.; Taherbhoy, A.M.; Duda, D.M.; Scott, D.C.; Borg, L.A.; Neale, G.; Murray, P.J.; Roussel, M.F.; et al. E2-RING expansion of the NEDD8 cascade confers specificity to cullin modification. Mol. Cell 2009, 33, 483-495.

64. Scott, D.C.; Monda, J.K.; Grace, C.R.; Duda, D.M.; Kriwacki, R.W.; Kurz, T.; Schulman, B.A. A dual E3 mechanism for Rub1 ligation to Cdc53. Mol. Cell 2010, 39, 784-796.

65. Kamura, T.; Conrad, M.N.; Yan, Q.; Conaway, R.C.; Conaway, J.W. The Rbx1 subunit of SCF and VHL E3 ubiquitin ligase activates Rub1 modification of cullins Cdc53 and Cul2. Genes Dev. 1999, 13, 2928-2933.

66. Ma, T.; Chen, Y.; Zhang, F.; Yang, C.Y.; Wang, S.; Yu, X. RNF111-dependent neddylation activates DNA damage-induced ubiquitination. Mol. Cell 2013, 49, 897-907. 
67. Kurz, T.; Ozlu, N.; Rudolf, F.; O’Rourke, S.M.; Luke, B.; Hofmann, K.; Hyman, A.A.; Bowerman, B.; Peter, M. The conserved protein DCN-1/DCN1p is required for cullin neddylation in C. elegans and S. cerevisiae. Nature 2005, 435, 1257-1261.

68. Kurz, T.; Chou, Y.C.; Willems, A.R.; Meyer-Schaller, N.; Hecht, M.L.; Tyers, M.; Peter, M.; Sicheri, F. DCN1 functions as a scaffold-type E3 ligase for cullin neddylation. Mol. Cell 2008, 29, 23-35.

69. Kim, A.Y.; Bommelje, C.C.; Lee, B.E.; Yonekawa, Y.; Choi, L.; Morris, L.G.; Huang, G.; Kaufman, A.; Ryan, R.J.; Hao, B.; et al. SCCRO (DCUN1D1) is an essential component of the E3 complex for neddylation. J. Biol. Chem. 2008, 283, 33211-33220.

70. Meyer-Schaller, N.; Chou, Y.C.; Sumara, I.; Martin, D.D.; Kurz, T.; Katheder, N.; Hofmann, K.; Berthiaume, L.G.; Sicheri, F.; Peter, M. The human DCN1-like protein DCNL3 promotes Cul3 neddylation at membranes. Proc. Natl. Acad. Sci. USA 2009, 106, 12365-12370.

71. Monda, J.K.; Scott, D.C.; Miller, D.J.; Lydeard, J.; King, D.; Harper, J.W.; Bennett, E.J.; Schulman, B.A. Structural conservation of distinctive N-terminal acetylation-dependent interactions across a family of mammalian NEDD8 ligation enzymes. Structure 2013, 21, 42-53.

72. Huang, G.; Kaufman, A.J.; Ramanathan, Y.; Singh, B. SCCRO (DCUN1D1) promotes nuclear translocation and assembly of the neddylation E3 complex. J. Biol. Chem. 2011, 286, 10297-10304.

73. Huang, G.; Stock, C.; Bommelje, C.C.; Weeda, V.B.; Shah, K.; Bains, S.; Buss, E.; Shaha, M.; Rechler, W.; Ramanathan, S.Y.; et al. SCCRO3 (DCUN1D3) antagonizes the neddylation and oncogenic activity of SCCRO (DCUN1D1). J. Biol. Chem. 2014, 289, 34728-34742.

74. Xirodimas, D.P.; Saville, M.K.; Bourdon, J.C.; Hay, R.T.; Lane, D.P. MDM2-mediated NEDD8 conjugation of p53 inhibits its transcriptional activity. Cell 2004, 118, 83-97.

75. Oved, S.; Mosesson, Y.; Zwang, Y.; Santonico, E.; Shtiegman, K.; Marmor, M.D.; Kochupurakkal, B.S.; Katz, M.; Lavi, S.; Cesareni, G.; et al. Conjugation to Nedd8 instigates ubiquitylation and down-regulation of activated receptor tyrosine kinases. J. Biol. Chem. 2006, $281,21640-21651$.

76. Zuo, W.; Huang, F.; Chiang, Y.J.; Li, M.; Du, J.; Ding, Y.; Zhang, T.; Lee, H.W.; Jeong, L.S.; Chen, Y.; et al. c-Cbl-mediated neddylation antagonizes ubiquitination and degradation of the TGF-beta type II receptor. Mol. Cell 2013, 49, 499-510.

77. Rabut, G.; Le Dez, G.; Verma, R.; Makhnevych, T.; Knebel, A.; Kurz, T.; Boone, C.; Deshaies, R.J.; Peter, M. The TFIIH subunit Tfb3 regulates cullin neddylation. Mol. Cell 2011, 43, 488-495.

78. Noguchi, K.; Okumura, F.; Takahashi, N.; Kataoka, A.; Kamiyama, T.; Todo, S.; Hatakeyama, S. TRIM40 promotes neddylation of IKKgamma and is downregulated in gastrointestinal cancers. Carcinogenesis 2011, 32, 995-1004.

79. Xie, P.; Zhang, M.; He, S.; Lu, K.; Chen, Y.; Xing, G.; Lu, Y.; Liu, P.; Li, Y.; Wang, S.; et al. The covalent modifier Nedd8 is critical for the activation of Smurf1 ubiquitin ligase in tumorigenesis. Nat. Commun. 2014, doi:10.1038/ncomms4733.

80. Gan-Erdene, T.; Nagamalleswari, K.; Yin, L.; Wu, K.; Pan, Z.Q.; Wilkinson, K.D. Identification and characterization of DEN1, a deneddylase of the ULP family. J. Biol. Chem. 2003, 278, 28892-28900.

81. Mergner, J.; Heinzlmeir, S.; Kuster, B.; Schwechheimer, C. DENEDDYLASE1 deconjugates NEDD8 from non-cullin protein substrates in Arabidopsis thaliana. Plant Cell 2015, 27, 741-753. 
82. Christmann, M.; Schmaler, T.; Gordon, C.; Huang, X.; Bayram, O.; Schinke, J.; Stumpf, S.; Dubiel, W.; Braus, G.H. Control of multicellular development by the physically interacting deneddylases DEN1/DENA and COP9 signalosome. PLoS Genet. 2013, 9, e1003275.

83. Lydeard, J.R.; Schulman, B.A.; Harper, J.W. Building and remodelling Cullin-RING E3 ubiquitin ligases. EMBO Rep. 2013, 14, 1050-1061.

84. Hori, T.; Osaka, F.; Chiba, T.; Miyamoto, C.; Okabayashi, K.; Shimbara, N.; Kato, S.; Tanaka, K. Covalent modification of all members of human cullin family proteins by NEDD8. Oncogene 1999, 18, 6829-6834.

85. Pan, Z.Q.; Kentsis, A.; Dias, D.C.; Yamoah, K.; Wu, K. Nedd8 on cullin: Building an expressway to protein destruction. Oncogene 2004, 23, 1985-1997.

86. Duda, D.M.; Borg, L.A.; Scott, D.C.; Hunt, H.W.; Hammel, M.; Schulman, B.A. Structural insights into NEDD8 activation of cullin-RING ligases: Conformational control of conjugation. Cell 2008, 134, 995-1006.

87. Soucy, T.A.; Smith, P.G.; Milhollen, M.A.; Berger, A.J.; Gavin, J.M.; Adhikari, S.; Brownell, J.E.; Burke, K.E.; Cardin, D.P.; Critchley, S.; et al. An inhibitor of NEDD8-activating enzyme as a new approach to treat cancer. Nature 2009, 458, 732-736.

88. Brownell, J.E.; Sintchak, M.D.; Gavin, J.M.; Liao, H.; Bruzzese, F.J.; Bump, N.J.; Soucy, T.A.; Milhollen, M.A.; Yang, X.; Burkhardt, A.L.; et al. Substrate-assisted inhibition of ubiquitin-like protein-activating enzymes: The NEDD8 E1 inhibitor MLN4924 forms a NEDD8-AMP mimetic in situ. Mol. Cell 2010, 37, 102-111.

89. Enchev, R.I.; Scott, D.C.; da Fonseca, P.C.; Schreiber, A.; Monda, J.K.; Schulman, B.A.; Peter, M.; Morris, E.P. Structural basis for a reciprocal regulation between SCF and CSN. Cell Rep. 2012, 2, $616-627$.

90. Liu, J.; Furukawa, M.; Matsumoto, T.; Xiong, Y. NEDD8 modification of CUL1 dissociates p120 (CAND1), an inhibitor of CUL1-SKP1 binding and SCF ligases. Mol. Cell 2002, 10, 1511-1518.

91. Schmidt, M.W.; McQuary, P.R.; Wee, S.; Hofmann, K.; Wolf, D.A. F-box-directed CRL complex assembly and regulation by the CSN and CAND1. Mol. Cell 2009, 35, 586-597.

92. Pierce, N.W.; Lee, J.E.; Liu, X.; Sweredoski, M.J.; Graham, R.L.; Larimore, E.A.; Rome, M.; Zheng, N.; Clurman, B.E.; Hess, S.; et al. Cand1 promotes assembly of new SCF complexes through dynamic exchange of F box proteins. Cell 2013, 153, 206-215.

93. Zemla, A.; Thomas, Y.; Kedziora, S.; Knebel, A.; Wood, N.T.; Rabut, G.; Kurz, T. CSN- and CAND1-dependent remodelling of the budding yeast SCF complex. Nat. Commun. 2013, doi:10.1038/ncomms2628.

94. Wu, S.; Zhu, W.; Nhan, T.; Toth, J.I.; Petroski, M.D.; Wolf, D.A. CAND1 controls in vivo dynamics of the cullin 1-RING ubiquitin ligase repertoire. Nat. Commun. 2013, doi:10.1038/ncomms2636.

95. Bennett, E.J.; Rush, J.; Gygi, S.P.; Harper, J.W. Dynamics of cullin-RING ubiquitin ligase network revealed by systematic quantitative proteomics. Cell 2010, 143, 951-965.

96. Fischer, E.S.; Scrima, A.; Bohm, K.; Matsumoto, S.; Lingaraju, G.M.; Faty, M.; Yasuda, T.; Cavadini, S.; Wakasugi, M.; Hanaoka, F.; et al. The molecular basis of CRL4DDB2/CSA ubiquitin ligase architecture, targeting, and activation. Cell 2011, 147, 1024-1039. 
97. Emberley, E.D.; Mosadeghi, R.; Deshaies, R.J. Deconjugation of Nedd8 from Cul1 is directly regulated by Skp1-F-box and substrate, and the COP9 signalosome inhibits deneddylated SCF by a noncatalytic mechanism. J. Biol. Chem. 2012, 287, 29679-29689.

98. Zhou, C.; Wee, S.; Rhee, E.; Naumann, M.; Dubiel, W.; Wolf, D.A. Fission yeast COP9/signalosome suppresses cullin activity through recruitment of the deubiquitylating enzyme Ubp12p. Mol. Cell 2003, 11, 927-938.

99. Hetfeld, B.K.; Helfrich, A.; Kapelari, B.; Scheel, H.; Hofmann, K.; Guterman, A.; Glickman, M.; Schade, R.; Kloetzel, P.M.; Dubiel, W. The zinc finger of the CSN-associated deubiquitinating enzyme USP15 is essential to rescue the E3 ligase Rbx1. Curr. Biol. 2005, 15, 1217-1221.

100. David, S.S.; O’Shea, V.L.; Kundu, S. Base-excision repair of oxidative DNA damage. Nature 2007, 447, 941-950.

101. Jackson, S.P.; Bartek, J. The DNA-damage response in human biology and disease. Nature 2009, 461, 1071-1078.

102. Dellaire, G.; Bazett-Jones, D.P. Beyond repair foci: Subnuclear domains and the cellular response to DNA damage. Cell Cycle 2007, 6, 1864-1872.

103. Pinder, J.B.; Attwood, K.M.; Dellaire, G. Reading, writing, and repair: The role of ubiquitin and the ubiquitin-like proteins in DNA damage signaling and repair. Front. Genet. 2013, doi:10.3389/fgene.2013.00045.

104. Higa, L.A.; Mihaylov, I.S.; Banks, D.P.; Zheng, J.; Zhang, H. Radiation-mediated proteolysis of CDT1 by CUL4-ROC1 and CSN complexes constitutes a new checkpoint. Nat. Cell Biol. 2003, 5, 1008-1015.

105. Tomoda, K.; Kubota, Y.; Kato, J. Degradation of the cyclin-dependent-kinase inhibitor p27Kip1 is instigated by Jab1. Nature 1999, 398, 160-165.

106. Choi, H.H.; Guma, S.; Fang, L.; Phan, L.; Ivan, C.; Baggerly, K.; Sood, A.; Lee, M.H. Regulating the stability and localization of CDK inhibitor p27(Kip1) via CSN6-COP1 axis. Cell Cycle 2015, 14, 2265-2273.

107. Lin, J.J.; Milhollen, M.A.; Smith, P.G.; Narayanan, U.; Dutta, A. NEDD8-targeting drug MLN4924 elicits DNA rereplication by stabilizing Cdt1 in S phase, triggering checkpoint activation, apoptosis, and senescence in cancer cells. Cancer Res. 2010, 70, 10310-10320.

108. Mackintosh, C.; Garcia-Dominguez, D.J.; Ordonez, J.L.; Ginel-Picardo, A.; Smith, P.G.; Sacristan, M.P.; de Alava, E. WEE1 accumulation and deregulation of S-phase proteins mediate MLN4924 potent inhibitory effect on Ewing sarcoma cells. Oncogene 2013, 32, 1441-1451.

109. Kastan, M.B.; Bartek, J. Cell-cycle checkpoints and cancer. Nature 2004, 432, 316-323.

110. Sengupta, S.; Harris, C.C. p53: Traffic cop at the crossroads of DNA repair and recombination. Nat. Rev. Mol. Cell Biol. 2005, 6, 44-55.

111. Bech-Otschir, D.; Kraft, R.; Huang, X.; Henklein, P.; Kapelari, B.; Pollmann, C.; Dubiel, W. COP9 signalosome-specific phosphorylation targets $\mathrm{p} 53$ to degradation by the ubiquitin system. EMBO J. 2001, 20, 1630-1639.

112. Oh, W.; Lee, E.W.; Sung, Y.H.; Yang, M.R.; Ghim, J.; Lee, H.W.; Song, J. Jab1 induces the cytoplasmic localization and degradation of $\mathrm{p} 53$ in coordination with Hdm2. J. Biol. Chem. 2006, $281,17457-17465$. 
113. Zhao, R.; Yeung, S.C.; Chen, J.; Iwakuma, T.; Su, C.H.; Chen, B.; Qu, C.; Zhang, F.; Chen, Y.T.; Lin, Y.L.; et al. Subunit 6 of the COP9 signalosome promotes tumorigenesis in mice through stabilization of MDM2 and is upregulated in human cancers. J. Clin. Investig. 2011, 121, 851-865.

114. Zhou, B.P.; Liao, Y.; Xia, W.; Zou, Y.; Spohn, B.; Hung, M.C. HER-2/neu induces p53 ubiquitination via Akt-mediated MDM2 phosphorylation. Nat. Cell Biol. 2001, 3, 973-982.

115. Abida, W.M.; Nikolaev, A.; Zhao, W.; Zhang, W.; Gu, W. FBXO11 promotes the Neddylation of p53 and inhibits its transcriptional activity. J. Biol. Chem. 2007, 282, 1797-1804.

116. Ebina, M.; Tsuruta, F.; Katoh, M.C.; Kigoshi, Y.; Someya, A.; Chiba, T. Myeloma overexpressed 2 (Myeov2) regulates L11 subnuclear localization through Nedd8 modification. PLoS ONE 2013, doi:10.1371/journal.pone.0065285.

117. Mahata, B.; Sundqvist, A.; Xirodimas, D.P. Recruitment of RPL11 at promoter sites of p53-regulated genes upon nucleolar stress through NEDD8 and in an MDM2-dependent manner. Oncogene 2012, 31, 3060-3071.

118. Llanos, S.; Serrano, M. Depletion of ribosomal protein L37 occurs in response to DNA damage and activates p53 through the L11/MDM2 pathway. Cell Cycle 2010, 9, 4005-4012.

119. Rubbi, C.P.; Milner, J. Disruption of the nucleolus mediates stabilization of p53 in response to DNA damage and other stresses. EMBO J. 2003, 22, 6068-6077.

120. Choi, H.H.; Gully, C.; Su, C.H.; Velazquez-Torres, G.; Chou, P.C.; Tseng, C.; Zhao, R.; Phan, L.; Shaiken, T.; Chen, J.; et al. COP9 signalosome subunit 6 stabilizes COP1, which functions as an E3 ubiquitin ligase for 14-3-3sigma. Oncogene 2011, 30, 4791-4801.

121. Reardon, J.T.; Sancar, A. Nucleotide excision repair. Prog. Nucleic Acid Res. Mol. Biol. 2005, 79, 183-235.

122. Kraemer, K.H.; DiGiovanna, J.J. Forty years of research on xeroderma pigmentosum at the US National Institutes of Health. Photochem. Photobiol. 2015, 91, 452-459.

123. Scrima, A.; Konickova, R.; Czyzewski, B.K.; Kawasaki, Y.; Jeffrey, P.D.; Groisman, R.; Nakatani, Y.; Iwai, S.; Pavletich, N.P.; Thoma, N.H. Structural basis of UV DNA-damage recognition by the DDB1-DDB2 complex. Cell 2008, 135, 1213-1223.

124. Sugasawa, K.; Okuda, Y.; Saijo, M.; Nishi, R.; Matsuda, N.; Chu, G.; Mori, T.; Iwai, S.; Tanaka, K.; Tanaka, K.; et al. UV-induced ubiquitylation of XPC protein mediated by UV-DDB-ubiquitin ligase complex. Cell 2005, 121, 387-400.

125. Scharer, O.D. Nucleotide excision repair in eukaryotes. Cold Spring Harb. Perspect. Biol. 2013, doi:10.1101/cshperspect.a012609.

126. Marteijn, J.A.; Lans, H.; Vermeulen, W.; Hoeijmakers, J.H. Understanding nucleotide excision repair and its roles in cancer and ageing. Nat. Rev. Mol. Cell Biol. 2014, 15, 465-481.

127. De Laat, W.L.; Appeldoorn, E.; Sugasawa, K.; Weterings, E.; Jaspers, N.G.; Hoeijmakers, J.H. DNA-binding polarity of human replication protein A positions nucleases in nucleotide excision repair. Genes Dev. 1998, 12, 2598-2609.

128. Fousteri, M.; Mullenders, L.H. Transcription-coupled nucleotide excision repair in mammalian cells: Molecular mechanisms and biological effects. Cell Res. 2008, 18, 73-84.

129. Zhao, Y.; Sun, Y. CUL4B ubiquitin ligase in mouse development: A model for human X-linked mental retardation syndrome? Cell Res. 2012, 22, 1224-1226. 
130. Groisman, R.; Kuraoka, I.; Chevallier, O.; Gaye, N.; Magnaldo, T.; Tanaka, K.; Kisselev, A.F.; Harel-Bellan, A.; Nakatani, Y. CSA-dependent degradation of CSB by the ubiquitin-proteasome pathway establishes a link between complementation factors of the Cockayne syndrome. Genes Dev. 2006, 20, 1429-1434.

131. Liu, L.; Lee, S.; Zhang, J.; Peters, S.B.; Hannah, J.; Zhang, Y.; Yin, Y.; Koff, A.; Ma, L.; Zhou, P. CUL4A abrogation augments DNA damage response and protection against skin carcinogenesis. Mol. Cell 2009, 34, 451-460.

132. Takedachi, A.; Saijo, M.; Tanaka, K. DDB2 complex-mediated ubiquitylation around DNA damage is oppositely regulated by XPC and $\mathrm{Ku}$ and contributes to the recruitment of XPA. Mol. Cell. Biol. 2010, 30, 2708-2723.

133. Poulsen, S.L.; Hansen, R.K.; Wagner, S.A.; van Cuijk, L.; van Belle, G.J.; Streicher, W.; Wikstrom, M.; Choudhary, C.; Houtsmuller, A.B.; Marteijn, J.A.; et al. RNF111/Arkadia is a SUMO-targeted ubiquitin ligase that facilitates the DNA damage response. J. Cell Biol. 2013, 201, 797-807.

134. Van Cuijk, L.; van Belle, G.J.; Turkyilmaz, Y.; Poulsen, S.L.; Janssens, R.C.; Theil, A.F.; Sabatella, M.; Lans, H.; Mailand, N.; Houtsmuller, A.B.; et al. SUMO and ubiquitin-dependent XPC exchange drives nucleotide excision repair. Nat. Commun. 2015, doi:10.1038/ncomms8499.

135. Wang, Q.E.; Zhu, Q.; Wani, G.; El-Mahdy, M.A.; Li, J.; Wani, A.A. DNA repair factor XPC is modified by SUMO-1 and ubiquitin following UV irradiation. Nucleic Acids Res. 2005, 33, 4023-4034.

136. Ng, J.M.; Vermeulen, W.; van der Horst, G.T.; Bergink, S.; Sugasawa, K.; Vrieling, H.; Hoeijmakers, J.H. A novel regulation mechanism of DNA repair by damage-induced and RAD23-dependent stabilization of xeroderma pigmentosum group C protein. Genes Dev. 2003, 17, 1630-1645.

137. Raasi, S.; Pickart, C.M. Rad23 ubiquitin-associated domains (UBA) inhibit 26 S proteasome-catalyzed proteolysis by sequestering lysine 48-linked polyubiquitin chains. J. Biol. Chem. 2003, 278, 8951-8959.

138. Ortolan, T.G.; Chen, L.; Tongaonkar, P.; Madura, K. Rad23 stabilizes Rad4 from degradation by the Ub/proteasome pathway. Nucleic Acids Res. 2004, 32, 6490-6500.

139. Heessen, S.; Masucci, M.G.; Dantuma, N.P. The UBA2 domain functions as an intrinsic stabilization signal that protects Rad23 from proteasomal degradation. Mol. Cell 2005, 18, 225-235.

140. Bergink, S.; Toussaint, W.; Luijsterburg, M.S.; Dinant, C.; Alekseev, S.; Hoeijmakers, J.H.; Dantuma, N.P.; Houtsmuller, A.B.; Vermeulen, W. Recognition of DNA damage by XPC coincides with disruption of the XPC-RAD23 complex. J. Cell Biol. 2012, 196, 681-688.

141. Bregman, D.B.; Halaban, R.; van Gool, A.J.; Henning, K.A.; Friedberg, E.C.; Warren, S.L. UV-induced ubiquitination of RNA polymerase II: A novel modification deficient in Cockayne syndrome cells. Proc. Natl. Acad. Sci. USA 1996, 93, 11586-11590.

142. Ratner, J.N.; Balasubramanian, B.; Corden, J.; Warren, S.L.; Bregman, D.B. Ultraviolet radiation-induced ubiquitination and proteasomal degradation of the large subunit of RNA polymerase II. Implications for transcription-coupled DNA repair. J. Biol. Chem. 1998, 273, 5184-5189. 
143. Schwertman, P.; Lagarou, A.; Dekkers, D.H.; Raams, A.; van der Hoek, A.C.; Laffeber, C.; Hoeijmakers, J.H.; Demmers, J.A.; Fousteri, M.; Vermeulen, W.; et al. UV-sensitive syndrome protein UVSSA recruits USP7 to regulate transcription-coupled repair. Nat. Genet. 2012, 44, 598-602.

144. Zhang, X.; Horibata, K.; Saijo, M.; Ishigami, C.; Ukai, A.; Kanno, S.; Tahara, H.; Neilan, E.G.; Honma, M.; Nohmi, T.; et al. Mutations in UVSSA cause UV-sensitive syndrome and destabilize ERCC6 in transcription-coupled DNA repair. Nat. Genet. 2012, 44, 593-597.

145. Rao, F.; Xu, J.; Khan, A.B.; Gadalla, M.M.; Cha, J.Y.; Xu, R.; Tyagi, R.; Dang, Y.; Chakraborty, A.; Snyder, S.H. Inositol hexakisphosphate kinase-1 mediates assembly/disassembly of the CRL4-signalosome complex to regulate DNA repair and cell death. Proc. Natl. Acad. Sci. USA 2014, 111, 16005-16010.

146. Matsuda, N.; Azuma, K.; Saijo, M.; Iemura, S.; Hioki, Y.; Natsume, T.; Chiba, T.; Tanaka, K.; Tanaka, K. DDB2, the xeroderma pigmentosum group E gene product, is directly ubiquitylated by Cullin 4A-based ubiquitin ligase complex. DNA Repair 2005, 4, 537-545.

147. Tomasz, M.; Palom, Y. The mitomycin bioreductive antitumor agents: Cross-linking and alkylation of DNA as the molecular basis of their activity. Pharmacol. Ther. 1997, 76, 73-87.

148. Pan, Y.; Zhang, Q.; Atsaves, V.; Yang, H.; Claret, F.X. Suppression of Jab1/CSN5 induces radio- and chemo-sensitivity in nasopharyngeal carcinoma through changes to the DNA damage and repair pathways. Oncogene 2013, 32, 2756-2766.

149. Ciccia, A.; Elledge, S.J. The DNA damage response: Making it safe to play with knives. Mol. Cell 2010, 40, 179-204.

150. Ochi, T.; Wu, Q.; Blundell, T.L. The spatial organization of non-homologous end joining: From bridging to end joining. DNA Repair 2014, 17, 98-109.

151. Lieber, M.R. The mechanism of double-strand DNA break repair by the nonhomologous DNA end-joining pathway. Annu. Rev. Biochem. 2010, 79, 181-211.

152. Heyer, W.D.; Ehmsen, K.T.; Liu, J. Regulation of homologous recombination in eukaryotes. Annu. Rev. Genet. 2010, 44, 113-139.

153. Kass, E.M.; Jasin, M. Collaboration and competition between DNA double-strand break repair pathways. FEBS Lett. 2010, 584, 3703-3708.

154. Shibata, A.; Jeggo, P.A. DNA double-strand break repair in a cellular context. Clin. Oncol. 2014, 26, 243-249.

155. Waters, C.A.; Strande, N.T.; Wyatt, D.W.; Pryor, J.M.; Ramsden, D.A. Nonhomologous end joining: A good solution for bad ends. DNA Repair 2014, 17, 39-51.

156. Caldecott, K.W. Single-strand break repair and genetic disease. Nat. Rev. Genet. 2008, 9, 619-631.

157. McVey, M.; Lee, S.E. MMEJ repair of double-strand breaks (director's cut): Deleted sequences and alternative endings. Trends Genet. 2008, 24, 529-538.

158. Jimeno, S.; Fernandez-Avila, M.J.; Cruz-Garcia, A.; Cepeda-Garcia, C.; Gomez-Cabello, D.; Huertas, P. Neddylation inhibits CtIP-mediated resection and regulates DNA double strand break repair pathway choice. Nucleic Acids Res. 2015, 43, 987-999.

159. Shinohara, A.; Ogawa, H.; Ogawa, T. Rad51 protein involved in repair and recombination in S. cerevisiae is a RecA-like protein. Cell 1992, 69, 457-470. 
160. Karanam, K.; Kafri, R.; Loewer, A.; Lahav, G. Quantitative live cell imaging reveals a gradual shift between DNA repair mechanisms and a maximal use of HR in mid S phase. Mol. Cell 2012, 47, 320-329.

161. Escribano-Diaz, C.; Orthwein, A.; Fradet-Turcotte, A.; Xing, M.; Young, J.T.; Tkac, J.; Cook, M.A.; Rosebrock, A.P.; Munro, M.; Canny, M.D.; et al. A cell cycle-dependent regulatory circuit composed of 53BP1-RIF1 and BRCA1-CtIP controls DNA repair pathway choice. Mol. Cell 2013, 49, 872-883.

162. De Jager, M.; Dronkert, M.L.; Modesti, M.; Beerens, C.E.; Kanaar, R.; van Gent, D.C. DNA-binding and strand-annealing activities of human Mre11: Implications for its roles in DNA double-strand break repair pathways. Nucleic Acids Res. 2001, 29, 1317-1325.

163. Paull, T.T.; Gellert, M. The 3' to 5' exonuclease activity of Mre 11 facilitates repair of DNA double-strand breaks. Mol. Cell 1998, 1, 969-979.

164. Paull, T.T.; Gellert, M. Nbs1 potentiates ATP-driven DNA unwinding and endonuclease cleavage by the Mre11/Rad50 complex. Genes Dev. 1999, 13, 1276-1288.

165. Sartori, A.A.; Lukas, C.; Coates, J.; Mistrik, M.; Fu, S.; Bartek, J.; Baer, R.; Lukas, J.; Jackson, S.P. Human CtIP promotes DNA end resection. Nature 2007, 450, 509-514.

166. Limbo, O.; Chahwan, C.; Yamada, Y.; de Bruin, R.A.; Wittenberg, C.; Russell, P. Ctp1 is a cell-cycle-regulated protein that functions with Mre11 complex to control double-strand break repair by homologous recombination. Mol. Cell 2007, 28, 134-146.

167. El-Khamisy, S.F.; Masutani, M.; Suzuki, H.; Caldecott, K.W. A requirement for PARP-1 for the assembly or stability of XRCC1 nuclear foci at sites of oxidative DNA damage. Nucleic Acids Res. 2003, 31, 5526-5533.

168. Mortusewicz, O.; Rothbauer, U.; Cardoso, M.C.; Leonhardt, H. Differential recruitment of DNA Ligase I and III to DNA repair sites. Nucleic Acids Res. 2006, 34, 3523-3532.

169. Wang, M.; Wu, W.; Wu, W.; Rosidi, B.; Zhang, L.; Wang, H.; Iliakis, G. PARP-1 and Ku compete for repair of DNA double strand breaks by distinct NHEJ pathways. Nucleic Acids Res. 2006, 34, 6170-6182.

170. Shibata, A.; Conrad, S.; Birraux, J.; Geuting, V.; Barton, O.; Ismail, A.; Kakarougkas, A.; Meek, K.; Taucher-Scholz, G.; Lobrich, M.; et al. Factors determining DNA double-strand break repair pathway choice in G2 phase. EMBO J. 2011, 30, 1079-1092.

171. Lemaitre, C.; Grabarz, A.; Tsouroula, K.; Andronov, L.; Furst, A.; Pankotai, T.; Heyer, V.; Rogier, M.; Attwood, K.M.; Kessler, P.; et al. Nuclear position dictates DNA repair pathway choice. Genes Dev. 2014, 28, 2450-2463.

172. Uziel, T.; Lerenthal, Y.; Moyal, L.; Andegeko, Y.; Mittelman, L.; Shiloh, Y. Requirement of the MRN complex for ATM activation by DNA damage. EMBO J. 2003, 22, 5612-5621.

173. Lee, J.H.; Paull, T.T. ATM activation by DNA double-strand breaks through the Mre11-Rad50-Nbs1 complex. Science 2005, 308, 551-554.

174. Burma, S.; Chen, D.J. Role of DNA-PK in the cellular response to DNA double-strand breaks. DNA Repair 2004, 3, 909-918.

175. Harper, J.W.; Elledge, S.J. The DNA damage response: Ten years after. Mol. Cell 2007, 28, 739-745.

176. Stracker, T.H.; Usui, T.; Petrini, J.H. Taking the time to make important decisions: The checkpoint effector kinases Chk1 and Chk2 and the DNA damage response. DNA Repair 2009, 8, 1047-1054. 
177. Burma, S.; Chen, B.P.; Murphy, M.; Kurimasa, A.; Chen, D.J. ATM phosphorylates histone H2AX in response to DNA double-strand breaks. J. Biol. Chem. 2001, 276, 42462-42467.

178. Stiff, T.; O’Driscoll, M.; Rief, N.; Iwabuchi, K.; Lobrich, M.; Jeggo, P.A. ATM and DNA-PK function redundantly to phosphorylate $\mathrm{H} 2 \mathrm{AX}$ after exposure to ionizing radiation. Cancer Res. 2004, 64, 2390-2396.

179. Stucki, M.; Jackson, S.P. $\gamma \mathrm{H} 2 \mathrm{AX}$ and MDC1: Anchoring the DNA-damage-response machinery to broken chromosomes. DNA Repair 2006, 5, 534-543.

180. Wei, D.; Li, H.; Yu, J.; Sebolt, J.T.; Zhao, L.; Lawrence, T.S.; Smith, P.G.; Morgan, M.A.; Sun, Y. Radiosensitization of human pancreatic cancer cells by MLN4924, an investigational NEDD8-activating enzyme inhibitor. Cancer Res. 2012, 72, 282-293.

181. Li, T.; Guan, J.; Huang, Z.; Hu, X.; Zheng, X. RNF168-mediated H2A neddylation antagonizes ubiquitylation of H2A and regulates DNA damage repair. J. Cell Sci. 2014, 127, 2238-2248.

182. Davies, O.R.; Forment, J.V.; Sun, M.; Belotserkovskaya, R.; Coates, J.; Galanty, Y.; Demir, M.; Morton, C.R.; Rzechorzek, N.J.; Jackson, S.P.; et al. CtIP tetramer assembly is required for DNA-end resection and repair. Nat. Struct. Mol. Biol. 2015, 22, 150-157.

183. Erker, Y.; Neyret-Kahn, H.; Seeler, J.S.; Dejean, A.; Atfi, A.; Levy, L. Arkadia, a novel SUMO-targeted ubiquitin ligase involved in PML degradation. Mol. Cell. Biol. 2013, 33, 2163-2177.

184. Brown, J.S.; Lukashchuk, N.; Sczaniecka-Clift, M.; Britton, S.; le Sage, C.; Calsou, P.; Beli, P.; Galanty, Y.; Jackson, S.P. Neddylation Promotes Ubiquitylation and Release of $\mathrm{Ku}$ from DNA-Damage Sites. Cell Rep. 2015, 11, 704-714.

185. Tian, L.; Peng, G.; Parant, J.M.; Leventaki, V.; Drakos, E.; Zhang, Q.; Parker-Thornburg, J.; Shackleford, T.J.; Dai, H.; Lin, S.Y.; et al. Essential roles of Jab1 in cell survival, spontaneous DNA damage and DNA repair. Oncogene 2010, 29, 6125-6137.

186. Hannss, R.; Dubiel, W. COP9 signalosome function in the DDR. FEBS Lett. 2011, 585, 2845-2852.

187. Siddik, Z.H. Cisplatin: Mode of cytotoxic action and molecular basis of resistance. Oncogene 2003, 22, 7265-7279.

188. Kouvaraki, M.A.; Rassidakis, G.Z.; Tian, L.; Kumar, R.; Kittas, C.; Claret, F.X. Jun activation domain-binding protein 1 expression in breast cancer inversely correlates with the cell cycle inhibitor p27(Kip1). Cancer Res. 2003, 63, 2977-2981.

189. Kouvaraki, M.A.; Korapati, A.L.; Rassidakis, G.Z.; Tian, L.; Zhang, Q.; Chiao, P.; Ho, L.; Evans, D.B.; Claret, F.X. Potential role of Jun activation domain-binding protein 1 as a negative regulator of p27kip1 in pancreatic adenocarcinoma. Cancer Res. 2006, 66, 8581-8589.

190. Rassidakis, G.Z.; Claret, F.X.; Lai, R.; Zhang, Q.; Sarris, A.H.; McDonnell, T.J.; Medeiros, L.J. Expression of $\mathrm{p} 27(\mathrm{Kip} 1)$ and c-Jun activation binding protein 1 are inversely correlated in systemic anaplastic large cell lymphoma. Clin. Cancer Res. 2003, 9, 1121-1128.

191. Wang, W.; Tang, M.; Zhang, L.; Xu, X.; Qi, X.; Yang, Y.; Jin, F.; Chen, B. Clinical implications of CSN6 protein expression and correlation with mutant-type P53 protein in breast cancer. Jpn. J. Clin. Oncol. 2013, 43, 1170-1176.

(C) 2015 by the authors; licensee MDPI, Basel, Switzerland. This article is an open access article distributed under the terms and conditions of the Creative Commons Attribution license (http://creativecommons.org/licenses/by/4.0/). 